\title{
Cooperation and endogenous repetition in an infinitely repeated social dilemma
}

\author{
Kenju Kamei ${ }^{1}$
}

Accepted: 17 February 2019 / Published online: 28 February 2019

(C) The Author(s) 2019

\begin{abstract}
Exogenously imposed infinite repetition is known to mitigate people's uncooperative behaviors in dilemma situations with partner matching through personal enforcement. One as yet unanswered question is whether people collectively choose to interact with each other under the partner matching condition when there exists an alternative possibility under random matching. In an indefinitely repeated public goods game framework, I let subjects democratically choose whether to (1) play with preassigned specific others for all rounds or to (2) play with randomly matched counterparts in every round. The experimental results revealed that most groups collectively opt for the partner matching protocol. The data also indicated that groups achieve a higher level of cooperation when they democratically select the partner matching protocol by voting, relative to when the same option is exogenously imposed. These findings imply that people's equilibrium selection may be affected by how the basic rules of games are introduced (endogenously or exogenously). The paper provides further evidence to suggest that the positive effect of democratic decision-making is stronger when the majority voting rule, rather than the unanimity rule, is applied.
\end{abstract}

Keywords Experiment · Public goods $\cdot$ Cooperation $\cdot$ Dilemma $\cdot$ Social norms Endogenous choices

\begin{abstract}
This project was supported by a grant-in-aid from the Nakayama Foundation for Human Science. I thank John Hey for his hospitality when I conducted the experiment at the University of York. I also thank Mark Wilson, an IT manager at the University of York, for support in managing the computers and the setup of the z-Tree software in the experimental sessions. I thank Pedro Dal Bó, Simon Gächter, and Todd Kaplan, audience of the Behavioural and Experimental Northeast Cluster seminar in April 2016 and the Copenhagen Workshop on Endogenous Institutions in Social Dilemmas in June 2018 for their comments. I also thank the editor, associate editor and two anonymous referees for useful comments that helped substantially improve the paper.
\end{abstract}

Electronic supplementary material The online version of this article (https://doi.org/10.1007/s0018 2-019-00663-7) contains supplementary material, which is available to authorized users.

Kenju Kamei

kenju.kamei@gmail.com; kenju.kamei@durham.ac.uk

1 Department of Economics and Finance, Durham University, Durham, UK 
JEL Classification C92 $\cdot \mathrm{H} 41 \cdot \mathrm{C} 73 \cdot \mathrm{D} 72$

\section{Introduction}

Collective action dilemmas, in which free riding is a strictly dominant strategy but mutual cooperation leads to a Pareto optimum, are ubiquitous in our real lives. A rich body of theoretical and experimental work has put considerable efforts into exploring how to overcome people's uncooperative behaviors in such dilemma situations. One of the most established behavioral findings during the last several decades is that people contribute to public goods to some degree even in one-shot games or in earlier rounds of repeated dilemma games (e.g., Ledyard 1995; Chaudhuri 2011). However, people cannot achieve high levels of cooperation in the absence of an institution that facilitates cooperation, such as peer-to-peer monetary or non-monetary punishment opportunities (e.g., Fehr and Gächter 2000; Masclet et al. 2003), because of serious tensions between cooperation and non-cooperation.

An important finding from research on dilemmas is that a person's decision to cooperate can be significantly altered if the game involves infinite repetition (the possibility to repeatedly interact with the same players until an unknown time period in the future). Theoretically, mutual cooperation, in addition to mutual defection, holds as an equilibrium outcome with partner matching through personal enforcement if the agents are sufficiently patient. Experimental tests for the theory of infinitely repeated games can be conducted using indefinitely repeated setups with a random continuation rule (Roth and Murnighan 1978). In previous studies, the evolution of cooperation has frequently been tested by using prisoner's dilemma games. Results from these past experiments show that when the partner matching protocol is used, indefinite repetition can indeed encourage people to behave more cooperatively under some conditions, compared with environments in which players know the precise length of the repeated games and mutual defection is the unique equilibrium (e.g., Roth and Murnighan 1978; Murnighan and Roth 1983; Feinberg and Husted 1993; Dal Bó 2005; Duffy and Ochs 2009; Dal Bó and Fréchette 2011). ${ }^{1}$ However, not everyone chooses to cooperate in many cases even under indefinite repetition. For instance, in Dal Bó (2005) the average cooperation rates range from 20 to $50 \%$ across almost all treatments even when prisoner's dilemma games are indefinitely repeated. In Dal Bó and Fréchette (2011), cooperation does not evolve even with experience if the mutual cooperation outcome is only sub-game perfect but a cooperative action is not risk-dominant. Dal Bó and Fréchette (2011) further show that cooperation does not always evolve even when cooperation is a risk-dominant equilibrium action.

One possible channel that may boost cooperation in the partner matching environment is a process in which players themselves collectively decide to play with each

\footnotetext{
1 See Dal Bó and Fréchette (2018) for a survey. There are also some experiments that showed that indefinite repetition did not increase the level of cooperation compared with in finitely repeated environments (e.g., Lugovskyy et al. 2015).
} 
other under that matching protocol. In all the experiments listed above, the partner matching protocol was exogenously given to subjects by the experimenters. Democratic decision-making may, however, encourage subjects to select a strategy that leads to a high level of cooperation (and accordingly a high level of payoff) through signaling effects and the so-called democracy premium. The democracy premium is defined as the impact that democratic decision-making directly has on people's preferences and beliefs (excluding any instrumental effects it may have, such as selection bias and the effects of information).

This paper undertakes a two-step approach to study the impact of democracy in the context of infinitely repeated games. In the first step, I set up a random matching protocol (where people's interaction partners change from round to round) as an alternative option and then let groups select one protocol, partner or random matching. After that I identify the impact of democracy. People's collective choice of a matching protocol is an interesting question in itself, not only theoretically but also empirically. From a theoretical perspective, prior work has demonstrated that with infinite repetition, community enforcement can sustain cooperation if agents are sufficiently patient, even with random matching (e.g., Kandori, 1992; Ellison, 1994). Recent experimental literature in this area also shows that indefinite repetition may encourage people to cooperate even if no information regarding their interaction partners' past action choices is available. ${ }^{2}$ Nevertheless, mutual cooperation is theoretically easier to achieve with partner matching rather than with random matching, because a higher degree of patience (a higher discounting factor) is required for players to choose cooperation in the latter matching protocol. One may wonder whether, given a choice, subjects select the partner matching protocol with the aim of obtaining high payoffs through the emergence of strong cooperation norms. From the perspective of experimental research, there is also evidence from finitely repeated games to suggest that subjects achieve comparatively higher cooperation norms and payoffs under the partner matching, because repetition adds strategic incentives to cooperate [see, e.g., Fehr and Schurtenberger (2018) for a survey]. ${ }^{3,4}$ Nevertheless, to my knowledge, people's collective choices between the partner and random matching protocols remains hitherto unexplored. This paper is the first to study people's collective choices between the partner versus random matching protocol and then to study the consequences of its endogenous adoption of the partner matching protocol using a laboratory experiment.

\footnotetext{
${ }^{2}$ Experimental results with random matching are rather mixed and a consensus has not been established yet. While Camera and Casari (2009) found a positive impact of indefinite repetition, Duffy and Ochs (2009) and the N treatment in Kamei (2017) found no impact. There are also conflicting results from past studies for the impact of indefinite repetition when some information on interaction partners is disclosed. While Camera and Casari (2009), Stahl (2013) and Kamei (2017) found that cooperation evolved with reputational information, Duffy and Ochs (2009) found that it did not do so.

3 Also see Gächter et al. (2017) who recently showed that subjects' reputation building motives under the partner matching protocol are much larger in the provision (rather than maintenance) of a public good-which is the setup of my framework.

${ }^{4}$ Even in a finitely repeated dilemma game, theoretically people can sustain cooperation if a sufficiently large fraction of them believe that the peers are acting on non-standard strategies, such as the tit-for-tat strategy (Kreps et al. 1982).
} 
Examples where people collectively decide whether to form explicit groups (high continuation probabilities) or not (low continuation probabilities) are frequently observed, especially in small-group interactions. For example, charitable or voluntary groups that aim to improve the lives of the poor in a community may form and collectively decide to work together for an indefinite amount of time. Other examples include student groups that act for purposes such as environment protection, sports and political activities. These student groups are often active over an undefined time horizon. Do people prefer to continuously work with the same peers, or engage in activities without establishing such groupings? Does a collectively-made decision to interact together affect people's level of cooperation? Further, consider international organizations, such as the United Nations. These organizations are formed by countries that share a common vision (e.g., poverty alleviation) and the member countries carry out missions together to achieve a common goal. The composition of these member countries is fairly stable and members thus face a higher continuation probability when making decisions together, compared with when they act without being a member of such an organization. While I acknowledge that the use of the random matching protocol (an environment with a continuation probability of zero in which subjects are randomly assigned to a group and then interact with each other only once in each round) as an alternative may not perfectly capture these real-world situations, this protocol can approximate a broad range of the settings mentioned above. The simplest setup then, with two extreme choice sets (partner versus random matching), enables us to parsimoniously capture certain phenomena of theoretical interest.

Recent studies on endogenous choices of institutions can inform on subjects' possible voting behaviors. The literature, however, provides conflicting evidence and implies different behaviors. On the one hand, subjects may vote for the partner matching protocol because votes are known to be significantly affected by their material concerns (e.g., Kamei et al. 2015; Putterman et al. 2011). As discussed, subjects' levels of contributions are known to be higher in the partner matching than in the random matching protocol. Subjects may also select the partner matching protocol if democratic choice serves as a signal that members will cooperate with other group members in the supergame (e.g., Tyran and Feld 2006) because the high incentives to free ride under the random matching protocol are sacrificed (e.g., Aimone et al. 2013; Grimm and Mengel 2009). Alternatively, voting in favor of playing together may serve as an opportunity to indirectly persuade those who initially did not plan to cooperate away from defection (e.g., Cooper et al. 1992; Blume and Ortmann 2007). ${ }^{5}$ These voting functions may improve cooperation further. Possible democracy premiums may also make partner matching more attractive to subjects (e.g., Dal Bó et al. 2010; Kamei 2016; Sutter et al. 2010; Tyran and Feld 2006).

\footnotetext{
5 The "hit-and-run" strategy (i.e., defect and then escape from the current group members) is possible with the random matching protocol.
} 
On the other hand, Dal Bó et al. (2017) recently demonstrated that voters tend to underappreciate equilibrium effects when evaluating alternatives. In my context, voters may mistakenly believe that cooperation is still difficult to achieve with partner matching and that they may remain stuck in a matching with less-cooperative partners if the partner matching protocol is in effect. This misperception may increase the attractiveness of the random matching protocol to subjects. Nevertheless, while in Dal Bó et al. (2017) the payoff matrix of the stage game differs between the two voting options, I use the same stage game structure for the two voting choices and only vary the matching protocols. Thus, arguably less cognitive loads would be required to evaluate equilibrium effects in my study than in Dal Bó et al. (2017). Subjects may hence quickly learn to select the partner matching protocol.

In addition to the contribution to the literature on democratic choices, this study also contributes to the research agenda on endogenous group formation and partner choice. Cooperation is known to be more likely to evolve in dilemma games with fixed group size, if individuals are provided with both an ability to choose with whom they interact and sufficient information on other players' past behaviors (e.g., Coricelli et al. 2004; Page et al. 2005; Kamei and Putterman 2017). The evolution of cooperation is also likely to be seen in dilemma games with variable group size (by voting with your feet) when entry to a new group requires the group members' agreement (e.g., Ahn et al. 2008; Charness and Chun-Lei 2014), or when peer-to-peer sanctioning institutions are present (e.g., Gürerk et al. 2006; Nicklisch et al. 2016; Fehr and Williams 2018). None of these studies, however, focused on identifying the impact of democracy. Instead, they examined other factors, such as the beneficial effects of competition for trustworthy partners and subjects' reputation building behaviors. In contrast, the direct effect of democracy in selecting to play with fixed partners may itself partly account for the positive evidence.

I use a linear public goods game framework (also known as voluntary contribution mechanism). In groups of four, each subject is given a fixed endowment and decides simultaneously how much to contribute to their group in every round. I design three treatments: one for the control condition and the other two for the treatment conditions. The three treatments are identical, except for the implementation process of the matching protocols. In the control condition, subjects play the public good game indefinitely with three fixed individuals and no agreement procedure is available. By contrast, in the treatment conditions, subjects are randomly assigned to groups with three individuals at the onset, and then each group democratically decides whether they want to play the public goods game with each other (i) for all rounds subject to a random continuation rule or (ii) for one round only. Option (i) is a standard partner matching condition, whereas option (ii) is a standard random matching condition. If a group selects option (ii), the group is dissolved after the one-time interaction. In the following round, subjects will be randomly re-matched with three individuals from groups that selected option (ii), and play the one-shot public goods game. This process-dissolution, random matching and 
one-shot public goods game-continues with a fixed probability (the random continuation rule). Experimental parameters are set so that (a) contributing nothing for the group is a strictly dominant strategy if the stage game is played just once but (b) if the stage game is infinitely repeated it becomes a coordination game (where any symmetric, positive contribution situation is sustained as an equilibrium outcome). The two treatment conditions differ by voting rule: unanimity rule or majority rule. Under the unanimity rule, subjects repeat voting until they reach a consensus. Agreement procedures in some real interactions use unanimity rules (including the small-group interactions mentioned in the above examples, and various decisions made by international organizations such as the United Nations and by political unions such as the European Union). Some past experimental studies on the impact of democratic decision-making have modeled democratic processes by using similar unanimity rules, including Sutter et al. (2010). Under the majority rule, subjects cast votes once, and whichever protocol that receives at least three votes is implemented in a group. A majority rule is also widely used form of democratic decision-making and is also adopted in past experiments on democracy, including Dal Bó et al. (2010), Tyran and Feld (2006) and Kamei (2016). As all the design aspects except the voting rule are identical for the three treatments, I can also provide new evidence about the difference in the impact of democracy between the two voting rules.

The experiment reveals that, first, almost all groups choose the partner matching protocol by voting. This is consistent with the theory that sustaining a high level of cooperation is easier in the partner matching than in the random matching protocol. Second, regardless of whether the unanimity or majority rule is used, subjects contribute significantly more in the treatment conditions, compared with subjects in the control condition, where the same partner matching protocol is exogenously imposed on them. A detailed analysis suggests that the positive effect of voting is not due to selection effects (e.g., Tyran and Feld 2006; Dal Bó et al. 2010, 2015) but can be partly explained by higher beliefs formed by subjects in the treatment conditions, consistent with the idea of the signaling hypothesis (e.g., Tyran and Feld 2006) or of democracy premiums. This result implies that democratic decision-making may significantly affect subjects' equilibrium selection in an infinitely repeated public goods game by influencing their beliefs. Yet there is an interesting difference between the two voting rules: the impact of democracy is stronger when the majority, rather than the unanimity, rule is used. The strong impact of democracy persists within supergames under the majority rule, whereas the effect diminishes from round to round within supergames under the unanimity rule. There is also a clear sign of democracy premium on subjects' contribution behaviors under the majority rule: we observe positive impact on subjects' decision to contribute even after controlling for their beliefs.

The rest of the paper proceeds as follows: Sect. 2 describes the experimental design. Section 3 briefly provides theoretical considerations. Section 4 reports results, and Sect. 5 concludes. 


\section{Experimental design}

The design frame is an indefinitely repeated public goods game. The group size is four. Subjects play the indefinitely repeated game five times in each treatment. ${ }^{6}$ The repeated supergame design was chosen, instead of a one-shot supergame design, to explore how people's collective choices change from supergame to supergame and how the impact of democracy persists over time. I employ a standard random matching protocol across the supergames, i.e., at the onset of each supergame group compositions are randomly changed. The duration of each supergame is stochastically determined. I set the random continuation probability as 75\% (e.g., Dal Bó 2005): subjects in the $t$ th round of a given supergame will play the next round (i.e., round $t+1$ ) with a probability of $75 \%$ (the supergame ends with a probability of $25 \%$ ). The expected length of subjects' interactions is therefore $4(=1 /(1-0.75))$ rounds in each supergame. This feature of stochastic determination of the game duration is common knowledge to all subjects.

The experiment consists of two endogenous treatments, denoted as the "Endogenous, Unanimity" (ENDO-U) and "Endogenous, Majority" (ENDO-M) treatments, and one exogenous treatment, denoted as the "Exogenous" (EXO) treatment (Table 1). I adopt a between-subjects design, rather than a within-subjects design, because democratic decision-making may affect subjects' behaviors beyond the environment where subjects make decisions. This indirect effect of democratic decision-making is defined as the spill-over effect of democracy in Kamei (2016). Thus, we obtain cleaner data if we divide subjects into independent treatment and control groups and then let them play the game under only one condition than otherwise.

This paper's empirical strategies to identify the impact of democratic decisionmaking are as follows:

Strategy a To compare subjects' action choices in the 1st supergame between two treatments but use only the rounds that occurred in all sessions of the 1st supergame in the two treatments.

Strategy $\boldsymbol{b}$ To compare subjects' action choices in all supergames between the two treatments but use only the rounds that occurred in all sessions in the two treatments.

The strategies to compare subjects' behaviors in the common rounds between two treatments are employed because each supergame likely has a different length by session due to the random continuation rule. The data would not be comparable between sessions (and accordingly between the two treatments) if we use the complete dataset. With strategies $a$ and $b$, we most likely use the first round of each supergame to study the impact of democracy. Since I use the continuation probability of $75 \%$, the probability that at least two rounds occur in all sessions of two treatments for a comparison is: $(0.75)^{K} \times 100[\%]$, where $K$ is the number of sessions. As will be explained in Sect. 4, there are three sessions per treatment.

\footnotetext{
6 The term "phase" was used in the experiment to refer to indefinitely repeated game.
} 


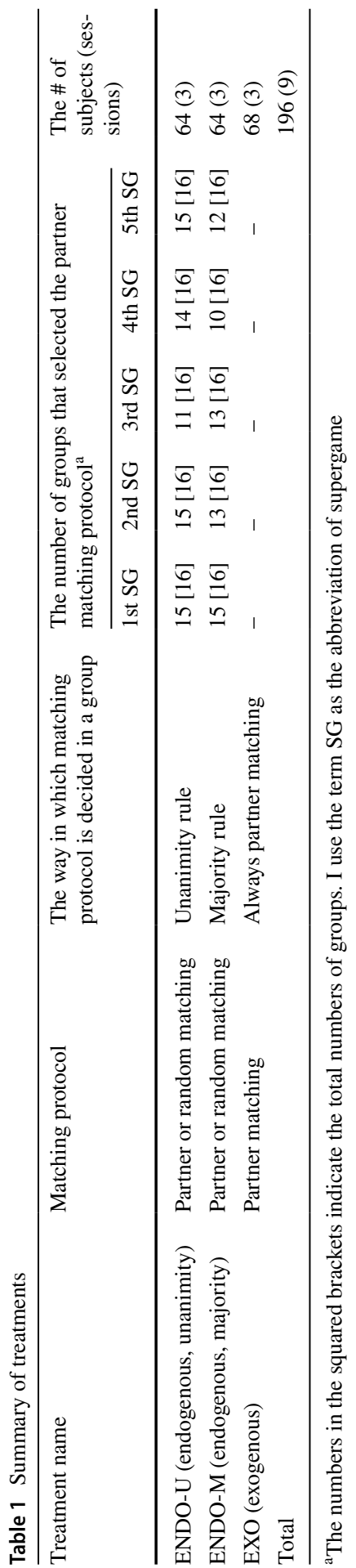


Thus, $K=6$. Hence, the probability that at least two rounds are realized during a given supergame in all the sessions in the ENDO- $U$ and EXO treatments, or in the ENDO-M and EXO treatments, is very low-only $17.8 \%\left(=(0.75)^{6} \times 100\right)$.

I perform analyses using strategy $a$, in addition to using strategy $b$, because data in the first supergame is cleaner than that of the 2 nd to 5 th supergames. Subjects' experiences in the first supergame would differ by session due to the random continuation rule. The difference in subjects' experiences in earlier supergames may affect their contribution and voting behaviors in the later supergames. I now explain each design aspect one by one.

\subsection{The stage game}

The stage game used in the experiment is a linear public goods game. In every round, subjects are each given an endowment of 20 points, and they simultaneously decide how to allocate it between their private and public accounts. The contribution amount must be an integer between 0 and 20. The sum of allocations to the private account and the public account must be 20 points. For each point that a subject allocates to her private account, she obtains one point as her payoff without affecting the payoffs of her group members. For each point she allocates to her public account, she and her three partners each obtain Marginal Per Capita Return (MPCR) $=0.4$ points as payoffs. In summary, when subject $i$ contributes $C_{i, t}$ to the public account in round $t$, she obtains the following payoff:

$$
20-C_{i, t}+r \sum_{j=1}^{N} C_{j, t},
$$

where $r=0.4(\mathrm{MPCR})$ and $N=4$ in this study. Note that $1 / N<r<1$.

\subsection{The treatment conditions}

In the ENDO-U treatment, after subjects are randomly assigned to a group of four in each supergame, they select a matching protocol by voting (Fig. 1a). The voting option is either partner matching (a continuation probability of 0.75 ) or random matching (a continuation probability of 0.00$).{ }^{7}$ The collective decision is made by a unanimity rule: four members of a group continue to vote until all members vote for the same option. The maximum number of the voting stages is $20{ }^{8}$ In the case that the four members do not agree on one option in the 20th voting stage, a majority rule is applied to determine the group's choice. ${ }^{9}$

In the ENDO-M treatment, subjects vote only once between the two matching protocols in each supergame. Whichever protocol receives at least three votes is

\footnotetext{
7 The two options were called "all periods in a given phase" and "one period" in the experiment.

${ }^{8}$ The maximum number of voting stages is set in order to avoid the duration of the experiment being too long.

${ }^{9}$ When votes are split equally between the two options in the 20th vote, one of them is randomly (i.e., with a probability of $50 \%$ ) selected by the computer.
} 
implemented in the group. In case of a tie, the computer selects one of the two protocols with a probability of $50 \%$ in that group.

If a group selects the partner matching protocol, then the four subjects interact with each other until the end of a given supergame. By contrast, if the group selects the random matching protocol, their interaction is one-shot. All groups that selected the random matching protocol are dissolved after the one-shot interaction. They are then randomly assigned to new groups of four among them and play the game with the three new peers once. The process of dissolution, random re-matching and oneshot public goods game repeats with a continuation probability of $75 \%$. $^{10}$

\subsection{The control condition}

In the EXO treatment, subjects have no opportunity to select a matching protocol. Instead, subjects are instructed that they will play with three pre-assigned members under partner matching in a given supergame (Fig. 1b). ${ }^{11}$

\subsection{Elicitation of beliefs}

As an additional analysis, I elicit subjects' beliefs in order to examine the motivation behind subjects' decisions to contribute. ${ }^{12}$ Specifically, in the ENDO-U and ENDO$\mathrm{M}$ treatments, after the voting stage and before moving on to the sequence of allocation stages, all subjects are asked about beliefs on the average contribution amount to the public account by their interaction peers during a given supergame. Likewise, subjects in the EXO treatment are also asked to state their beliefs on their interaction peers' average contribution amount before each supergame commences.

\footnotetext{
${ }^{10}$ If the number of groups that selected the random matching protocol is only one, then the four group members interact with each other for all rounds in the given supergame because there are no other groups to be dissolved. As an anonymous referee pointed out, this design aspect could affect subjects' behaviors if they realize that the number of groups that selected the random matching is sufficiently small because then the random matching becomes almost equivalent to the partner matching. Nevertheless, it is unlikely that this concern biased subjects' decisions in the experiment for the following two reasons. First, as will be explained in Sect. 4.1, most groups selected the partner matching protocol from the first supergame. Second, subjects were not informed how many groups selected the random matching protocol. As shown in Sect. 4.2, subjects' contribution behaviors were significantly different between the partner and random matching protocols. This suggests that subjects would likely have perceived the random matching protocol as different from the partner matching protocol.

${ }^{11}$ I acknowledge that there are other ways to design the control treatment. For instance, another possible way would be to assign each matching protocol stochastically to control groups with the actual percentages of groups which selected each option in the ENDO-U or ENDO-M treatment, without informing subjects of the percentages of stochastic implementation. I did not employ this method because subjects in the ENDO-U and ENDO-M treatments were able to guess the likelihood of these matching protocols being selected to some degree as their votes determine collective choices. Alternatively, we could stochastically impose one of the two matching protocols on control groups while notifying subjects the percentages of stochastic determination. However, this control treatment design is not perfect either considering that subjects in the ENDO-U and ENDO-M treatments are not given the information as to how many groups select the partner or random matching protocol.

12 The importance of beliefs when subjects choose actions has been experimentally demonstrated in finitely repeated setups (e.g., Selten and Stoecker 1986; Andreoni and Miller 1993; Kamei and Putterman 2017).
} 


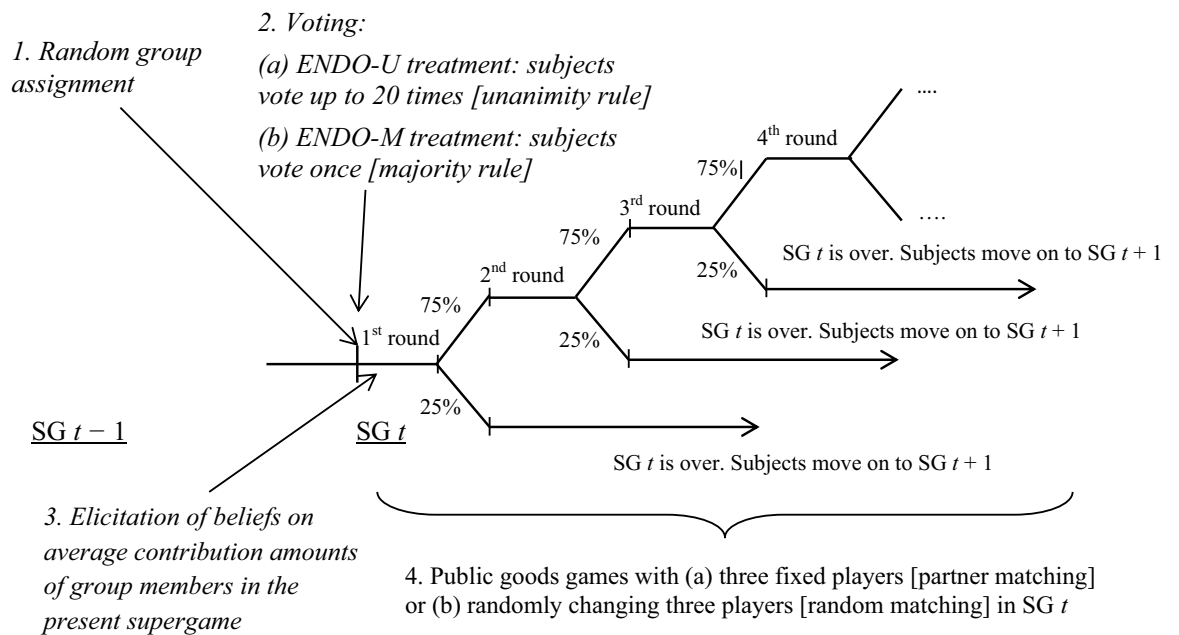

(a) The ENDO-U and ENDO-M treatments

1. Random group assignment

$\underline{\mathrm{SG} t-1}$

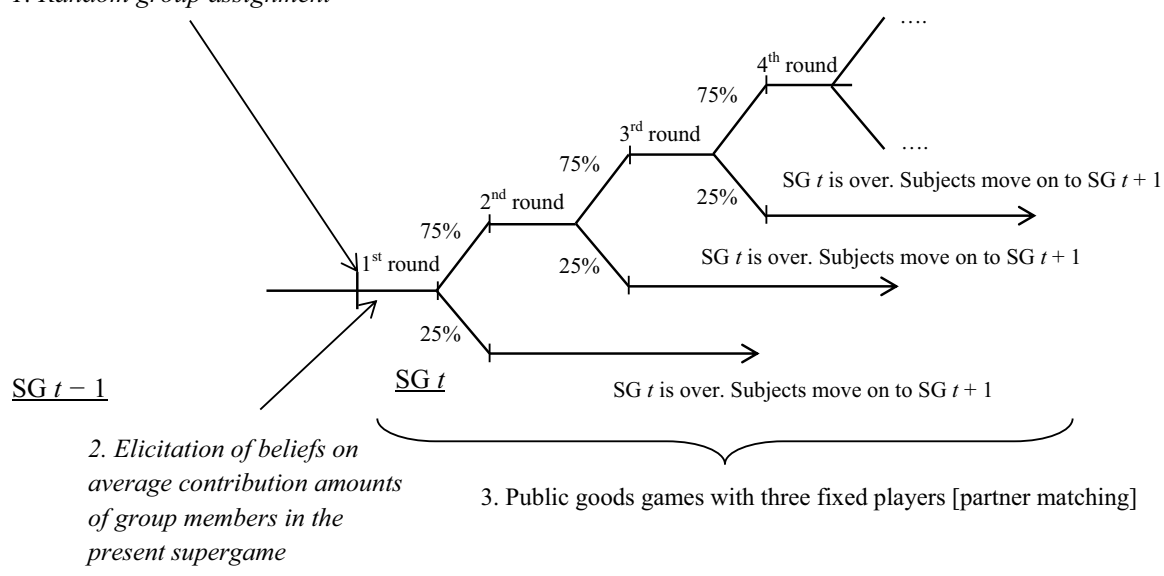

2. Elicitation of beliefs on average contribution amounts of group members in the or (b) randomly changing three players [random matching] in SG $t$

(b) The EXO treatment

Fig. 1 Experimental design

I note that the belief elicitation task is not incentivized in order to minimize its effects on subjects' action choices because this paper's first priority is on subjects' voting and their actual contribution behaviors. ${ }^{13}$ Possible side effects of incentivized

\footnotetext{
${ }^{13}$ See Sections (d) and (e) in Supplementary Appendix A for computer screen images for this elicitation task.
} 
belief elicitation methods have been documented [see, for example, Gächter and Renner (2010) for the detail]. ${ }^{14}$

\section{Theoretical considerations on subjects' behaviors}

The standard theory does not provide a point prediction in the experiment. In the EXO treatment, not only the mutual free-riding but also any symmetric, positive contribution situation holds as an equilibrium outcome since I adopt 0.75 as a continuation probability. To illustrate a possibility of the mutual full contribution equilibrium in this control treatment, suppose that all four individuals in a group have contributed the full endowment amounts $(E)$ to the public account before round $t$ and have been and will be using a grim trigger strategy. That is, a subject $i$ contributes $E$ points until she sees at least one instance of defection where one of the individuals in her group contributes less than $E$; once $i$ faces the defection she starts contributing zero points until the end of a given supergame. In this situation, if subject $i$ continues to follow the grim trigger strategy in and after round $t$, her expected payoff $\left(E\left[\pi_{i}\right]\right)$ is calculated as:

$$
E_{t}\left[\pi_{i}\right]^{\text {cooperate }}=\sum_{s=t}^{\infty} \delta^{s-t} \cdot \pi_{i, s}\left(c_{i, s}\right)=\frac{r \cdot N \cdot E}{1-\delta}=128,
$$

where $E=20, r$ is the MPCR $(=0.4), N$ is group size $(=4)$ and $\delta$ is the continuation probability $(=0.75)$. Alternatively, if she changes her strategy and contributes zero points in round $t$, her expected payoff is maximized by also contributing zero points in any round after round $t$ because the other three players will contribute zeros as they are following the grim trigger strategy. The maximum payoff is thus calculated as:

$$
E_{t}\left[\pi_{i}\right]^{\text {defect }}=E-0+r \cdot(N-1) \cdot E+\sum_{s=t+1}^{\infty} \delta^{s-t} \cdot \pi_{i, s}\left(c_{i, s}\right)=44+\frac{\delta \cdot E}{1-\delta}=104,
$$

which is less than the mutual full contribution payoff in Eq. (2). It is therefore not materially beneficial for $i$ to deviate from the mutual full contribution situation. Note that the threshold value of $\delta$ so that the mutual full contribution situation can be supported as an equilibrium outcome is 0.5 , which is much less than 0.75 .

There also exists a symmetric, positive, but less-than-full-contribution equilibrium for any contribution level $\xi \in\{1,2, \ldots, E\}$ in the EXO treatment. The existence

\footnotetext{
${ }^{14}$ Gächter and Renner (2010) let subjects play a finitely repeated linear public goods game with the same experimental parameters as this paper (the per-subject endowment is 20 points and the MPCR is $0.4)$. Their results indicated that although elicited beliefs were more accurate when they were incentivized than when they were not incentivized, the mean difference was only 0.59 points, and that the incentivized elicitation significantly influenced subjects' decision to contribute. If subjects' beliefs were not incentivized, by contrast, their contribution amounts were not significantly different from those in a treatment where beliefs were not elicited. Gächter and Renner (2010) suggest that "If the researcher is afraid that belief elicitation leads to behavioral results that he or she would not obtain when not asking for beliefs, then $[\ldots]$ belief elicitation should not be incentivized" (page 372 ).
} 
of such an equilibrium can be checked with the same logic that assumes the subjects' grim trigger strategy. With the symmetric contribution equilibrium with the contribution level of $\xi$ points, subject $i$ obtains a payoff as in Eq. (4):

$$
E_{t}\left[\pi_{i}\right]^{\text {continue to contribute } \xi \text { points }}=\sum_{s=t}^{\infty} \delta^{s-t} \cdot \pi_{i, s}(\xi)=\frac{E-\xi+r \cdot N \cdot \xi}{1-\delta} \text {. }
$$

If subject $i$, by contrast, contributes zero points to the public account in a given round, she obtains the following as maximum payoff:

$$
\begin{aligned}
E_{t}\left[\pi_{i}\right]^{\text {defect }} & =E-0+r \cdot(N-1) \cdot \xi+\sum_{s=t+1}^{\infty} \delta^{s-t} \cdot \pi_{i, s}(0) \\
& =E+r \cdot(N-1) \xi+\frac{\delta E}{1-\delta}
\end{aligned}
$$

Equations (4) and (5) suggest that $E_{t}\left[\pi_{i}\right]^{\text {continue to contribute } \xi \text { points }}>E_{t}\left[\pi_{i}\right]^{\text {defect }}$, regardless of the value of $\xi$, if $\delta>0.5$. ${ }^{15}$ We also see that Eq. (4) is monotonically increasing in the symmetric contribution level $\xi$. In other words, the strategic situation that subjects face is the one with Pareto-ranked multiple equilibria.

The same holds true also for groups that select the partner matching protocol in the ENDO-U and ENDO-M treatments. These groups face the same strategic situation with Pareto-ranked multiple equilibria.

Summary 1: Not only the mutual full free-riding situation, but also any symmetric, positive contribution situation holds as an equilibrium outcome in the EXO treatment. Subjects in groups that implemented the partner matching protocol in the ENDO-U and ENDO-M treatments face the same strategic situation as the subjects in the EXO treatment.

Subjects have stronger incentives to defect in groups where the random matching protocol is implemented because they can hit and run, considering that the respective groups will be dissolved after a given round and they may be matched with subjects from other groups in the following rounds. Following the logic of Kandori (1992), however, one instance of defection can spread very quickly to other subjects in groups with the random matching protocol if each subject employs a grim trigger strategy. Due to this contagion process, the symmetric, positive contribution situation with any level $\xi \in\{1,2, \ldots, E\}$, including the mutual full contribution situation, can be sustained as an equilibrium outcome. Incentives to defect depend on how many groups selected the random matching protocol. Taking an extreme example to illustrate, suppose that there are 24 subjects in the experiment and that all of the six groups selected the random matching protocol. As will be explained later, the number of groups per session was either five or six in the experiment. Because the incentive to defect is largest in this extreme situation, if the symmetric positive

15 The threshold $\delta$ is decreasing in the size of $N$ and also in the size of $r$. 
contribution situations can be supported as equilibrium outcomes in this situation, there is clearly no incentive for subject $i$ to deviate from the grim trigger strategy when the number of groups that selected the random matching protocol is less than six. As calculated in Appendix B, even in this extreme situation, when subject $i$ contributes less than $\xi$ points in round $t$, the percentage of full free-riders out of the other 23 subjects reaches around $90 \%$ by round $t+3$, even if the 23 subjects have contributed $\xi$ points until round $t$. Due to the rapid contagion of free-riding, the total expected payoff from defection is lower than the mutual cooperation payoff, which is $(E-\xi+r \cdot N \cdot \xi) /(1-\delta)$. This means that $i$ has no incentive to deviate and thus any symmetric contribution situation holds as an equilibrium outcome. These considerations are summarized as follows:

Summary 2: Regardless of how many groups select the random matching protocol, both mutual full free-riding situation and any symmetric, positive contribution situation (including the mutual full contribution situation) hold as equilibrium outcomes when the random matching protocol is implemented in a given supergame.

Despite the theoretical analyses contained in Summary 1 and Summary 2, we would expect that the symmetric contribution equilibrium for a given contribution level ( $\xi$ points) is more easily attained when the partner matching protocol, rather than the random matching protocol, is selected. This is because, with random matching, the threshold value of continuation probabilities above which the mutual contribution holds as an equilibrium outcome $\left(\bar{\delta}^{\text {random }}\right)$ is greater than or equal to that with partner matching $\left(\bar{\delta}^{\text {partner }}=0.5\right)$. Recall that group composition changes in every round among those who selected the random matching protocol. $\delta$ random would coincide with $\bar{\delta}^{\text {partner }}$ in the (somewhat unlikely) case that only one group selects the random matching protocol and the members of this specific group are aware of the fact that they are the only group that selected that matching protocol; in any other situation, $\bar{\delta}^{\text {random }}$ is always greater than $\bar{\delta}^{\text {partner }}$. This suggests that subjects' incentives to deviate are smaller with partner matching than in the random matching protocol. We can therefore summarize the difference in subjects' contribution behavior as follows:

Summary 3: Any given symmetric contribution situation is more easily attained in the partner matching than in the random matching protocol.

Summary 3 suggests that the average contribution in groups that select the partner matching protocol would be higher than that in groups that select the random matching protocol.

As already discussed in Sect. 1, we cannot provide definite predictions as to which of the two matching protocols groups select, although a larger fraction of studies seems to suggest that more groups would select the partner matching protocol. 
I also note that, notwithstanding Summary 1, subjects' contribution behavior under the partner matching protocol may be stronger in the ENDO-M and ENDO$\mathrm{U}$ treatments than in the EXO treatment, because voting for the partner matching protocol may serve as a signal that the subject wishes to forgo the high temptation to deviate under random matching (Aimone et al. 2013), ${ }^{16}$ and thus as a signal of their future contribution behavior (e.g. Tyran and Feld 2006). The democracy premium may also be present when groups collectively implement the partner matching protocol (Dal Bó et al. 2010; Kamei 2016; Markussen et al. 2014; Sutter et al. 2010; Tyran and Feld 2006). ${ }^{17}$ If the signaling effects and/or the democracy premium are significant, then, for example, beliefs about others' contributions formed by subjects under the partner matching protocol might be higher in the ENDO-U and ENDO$M$ treatments than in the EXO treatment. The positive effect of the democracy premium may even be compounded if democracy directly affects subjects' cooperation behaviors through a channel other than beliefs (e.g., Kamei 2016).

\section{Results}

The experiment was conducted at the Centre for Experimental Economics (EXEC) laboratory at the University of York in the United Kingdom from October to December 2015 and October 2016. ${ }^{18}$ All subjects were students at the University of York. In total, nine sessions - three for each treatment, were conducted. Each session consisted of five or six groups (20 or 24 subjects). Subjects voluntarily registered for and participated in the experiment. They were recruited by solicitation messages sent through hroot (Bock et al. 2014). No subject participated in more than one session. Client computers were separated from each other by three sufficiently tall partitions (one for the front and two for the sides). No communication was permitted throughout the experiment.

All experimental procedures except the instructions and comprehension questions were computerized. They were programmed in the z-Tree software (Fischbacher 2007). All instructions were neutrally framed (see Appendix A). Any words with positive or negative connotation (e.g., contribute, public goods) were avoided. At the onset of the experiment, the instructions were handed out to subjects and read aloud by the researcher. Subjects were then asked to answer comprehension questions to check their understanding of the experiment. At the end of the experiment, each subject was privately paid based on their interaction outcomes. The average per-subject payoff (including $£ 3$ for show-up fee) was 15.85 pounds sterling.

\footnotetext{
16 See Grimm and Mengel (2009) and Schneider and Weber (2013) also.

17 The presence of the democracy premium may depend on the distribution of income. All the papers cited here used setups where endowments were the same among subjects. The democracy premium was not observed in Kamei (2018), where subjects democratically selected a public goods game or a lottery contest when endowments were unequally distributed among the subjects.

18 I first conducted the ENDO-U and EXO treatments in 2015. I then conducted the ENDO-M treatment as the second experiment in October 2016.
} 


\subsection{Subjects' voting behavior}

I first examine subjects' vote outcomes in order to address the first research question (people's collective choice). First, the experimental results showed that most groups implemented the partner matching protocol from the first supergame (Table 1). Specifically, 15 out of 16 groups in each of the ENDO-U and ENDO-M treatments chose to play with the pre-assigned players for the full set of rounds in the first supergame. The percentages of groups that chose this option remained similar during the five supergames in the ENDO-U treatment, except for the 3rd supergame in which the percentage was slightly lower. ${ }^{19}$ The number of these groups declined slightly after the first supergame in the ENDO-M treatment, but the numbers hovered at high levels between ten and 13 groups during the 2 nd to 5 th supergames. The difference in the fraction of groups that selected the partner matching protocol is not significantly different between the two endogenous treatments in each supergame. ${ }^{20}$

Second, although we found overwhelming support for the partner matching protocol, the number of voting stages required for groups to agree on one of the two matching protocols differed substantially by group and session in the ENDO-U treatment (Part I in Appendix Table C.1). While 28.8\% and 25.0\% of groups reached unanimous agreement in the first and second voting stages, respectively, $32.5 \%$ of group decisions required at least five voting stages. Similarly, the number of supports for the partner matching protocol differs by groups under the majority rule (Part II in Appendix Table C.1). 23.8\% of groups had all four members' supports, while $46.3 \%$ and $25.0 \%$ of groups had three and two members' supports, respectively, in the ENDO-M treatment (the remaining 5\% of groups had one support for the partner matching and instead implemented the random matching protocol).

Result 1 (i) Most groups implemented the partner matching protocol in each supergame. (ii) Nevertheless, there was substantial variation across groups in the number of voting stages required to agree on the partner matching protocol in the ENDO-U treatment and the number of supports for that protocol in the ENDO-M treatment.

\footnotetext{
19 As an anonymous referee pointed out, some readers may think that if subjects experienced a large number of voting stages due to disagreement and ended up by selecting the partner matching protocol in a given supergame, in a later supergame the partner matching protocol might become a focal point and subjects may just vote for it quickly to avoid a lengthy voting process. Or worse, there may even emerge an experimenter demand effect that encourages subjects to vote for the partner matching protocol. There is no evidence in the data, however, to support this pattern (see Part I of Appendix Table C.1). The average numbers of voting stages required to reach a consensus were $3.31,3.13,4.56,5.63$, and 6.13 in the 1st, 2nd, 3rd, 4th and 5th supergames, respectively. The numbers of groups that reached a consensus in the very first voting stage were 5, 6, 3, 5, and 4 in the $1 \mathrm{st}$, 2nd, 3rd, 4th and 5th supergames, respectively.

${ }^{20} p$-values based on two-sided Fisher's exact tests for the null that the fractions are equal for the two treatments are $1.000,0.600,0.685,0.220$, and 0.333 in the $1 \mathrm{st}, 2 \mathrm{nd}, 3 \mathrm{rd}$, 4 th and 5 th supergames, respectively.
} 


\subsection{The impact of democracy}

I now move on to identify the impact of democratic decision-making on subjects' contribution behaviors. ${ }^{21}$ We usually need to take care of selection effects for this purpose (e.g., Tyran and Feld 2006; Dal Bó et al. 2010, 2015). The collective preference exhibited by almost all groups to commit to a longer partnership from the 1st supergame [Result 1(i)], however, means that no subsample unrepresentative of the population emerges from the voting process in the ENDO-U or ENDO-M treatment. This observation suggests that there is little concern of selection bias in the data, although I conducted some robustness checks nevertheless as explained later in this subsection. ${ }^{22}$ By contrast, it may be desirable to control for the possibility of correlated subject choices within sessions especially for the ENDO-U treatment since the duration of voting stages differed by session (Sect. 4.1). To address this possibility, I cluster standard errors at the session level when analyzing individuallevel data.

My method to identify the impact of democracy is to use the empirical strategies $a$ and $b$ discussed in Sect. 2. As expected, in each supergame, only the first round was the common period that occurred for all the six sessions in the ENDO-U and the EXO treatments. ${ }^{23}$ The same holds also for the six sessions in the ENDO-M and EXO treatments. Hence, I use round 1 behaviors in each supergame to compare contribution decisions between the ENDO-U and EXO treatments, and between the ENDO-M and EXO treatments.

Table 2 summarizes the average round 1 contribution amount by session, matching protocol and supergame. The average contribution in the 1st supergame is 10.97 points in the ENDO-U treatment when the groups selected the partner matching protocol. This is greater than the average contribution in the EXO treatment ( 9.19 points). The large difference in the average contribution between the two treatments persists until the 5th supergame. The average contribution under the partner matching is even higher in the ENDO-M treatment-12.47 points in the first supergame and 10.27 points on average across the five supergames. The average contributions in the ENDO-M treatment are 35.7, 30.4, 25.4, 36.6, and $34.8 \%$ higher than those in the EXO treatment in the 1st, 2nd, 3rd, 4th and 5th supergames, respectively.

\footnotetext{
21 Because average payoffs are the linear transformations of subjects' average contribution amounts based on Eq. (1), results are the same even if payoff data are used instead.

${ }^{22}$ Controlling for selection bias is required if a selection through voting occurs unlike Result 1(i). See Dal Bó, Foster and Putterman (2010) and Tyran and Feld (2006). Also see Dal Bó, Foster and Kamei (2015), who recently propose a new identification strategy for correcting selection bias in the case of majority voting.

23 The trends of subjects' round-by-round action choices by supergame and by session are provided in Appendix Figure C.1. As anticipated, the realized length of each indefinitely repeated game differed by session and supergame as often seen in indefinitely repeated game experiments. For instance, the 1 st supergame lasted for only one round in three out of the nine sessions conducted in this study.
} 
In order to ascertain the statistical significance of the impact of democracy, I conducted a regression analysis. Columns (1) and (4), and columns (2) and (5) of Table 3 report the estimation results when using data of the 1st supergame only (1st SG data, hereafter) and of all the five supergames (All SG data, hereafter), respectively. The dependent variable is subject $i$ 's contribution amount to the public account in round 1 . Only observations in groups which operated under the partner matching protocol were used. The independent variables include the Endo dummy variable, which equals 1 for the ENDO-U and ENDO-M treatments; and 0 for the EXO treatment. A tobit regression model is used for the estimation because subjects' contribution amounts are censored at 0 and $20 .{ }^{24}$ Standard errors are clustered by session for all the specifications. ${ }^{25}$ The specification in columns (1) and (4) includes only the Endo dummy, while in columns (2) and (5), the supergame number variable (which equals 1, 2, 3, 4, or 5) is also included to control for the trend across the supergames. Further, in columns (2) and (5), the interaction term between the supergame number variable and the Endo dummy is included as the across-supergame trend may differ by the treatment. Three clear patterns were found. First, letting subjects collectively choose the partner matching protocol helps enhance subjects' contributions significantly in the first supergame, regardless of the voting rule used [see columns (1) and (4)]. Second, the across-supergame trends in contributions are not different between the ENDO-U or ENDO-M treatment and the EXO treatment, and the positive effect of democratic decision-making persists across the supergames, regardless of the voting rule used [see columns (2) and (5)]. ${ }^{26}$ Third, the positive impact of democracy is stronger when the majority rule, rather than the unanimity rule, is used (see the coefficient estimates of the Endo dummy). ${ }^{27}$

\footnotetext{
${ }^{24}$ One drawback of using a tobit model is that there is no theoretically valid way to add individual random effects on top of session clustering. An alternative method to address this concern is to adopt an ordered probit regression model because subjects' choice set (contribution amount) is ordered: $\{0,1,2$, $\ldots, 20\}$. The ordered probit method allows researchers to include both clustering and individual random effects. I estimated the same specifications using individual random effects ordered probit regression with standard errors clustered by session ID as a robustness check. The results, found in Appendix Table C.2, are qualitatively similar to those in Table 3. As a further robustness check, I also ran a linear regression while including both session clustering and individual random effects, which again finds results qualitatively similar to those of Table 3 (the results are omitted to conserve space).

${ }^{25}$ Clustering by session is especially required for the All SG data because the random matching protocol is used for matching across the supergames.

${ }^{26}$ Results are similar when two-sided session average Mann-Whitney tests are used. The average round 1 contribution in the 1st supergame under the partner matching protocol is significantly higher in the ENDO-U or ENDO-M treatment than in the EXO treatment $(p=0.0495)$. The difference in the average contribution amount is also statistically significant between the endogenous and exogenous treatments when we use average round 1 contributions across all of the five supergames $(p=0.0495)$.

${ }^{27}$ The difference in the coefficient estimate of the Endo dummy between columns (1) and (4) is significant ( $p=0.0020$, two-sided $\mathrm{F}$ test), although the difference between columns (2) and (5) is not significant $(p=0.1787$, two-sided F test $)$.
} 
Table 2 Contribution amounts in each supergame

\begin{tabular}{|c|c|c|c|c|c|c|}
\hline & 1st SG & 2nd SG & 3rd SG & 4th SG & 5 th SG & All supergames \\
\hline \multicolumn{7}{|c|}{ (a) The ENDO-U treatment } \\
\hline \multicolumn{7}{|l|}{ Session 1} \\
\hline Partner matching & $10.96(6)$ & $9.95(5)$ & $8.67(3)$ & $6.67(6)$ & $5.96(6)$ & 8.36 \\
\hline Random matching & N/A (0) & $4.75(1)$ & $5.50(3)$ & N/A (0) & N/A (0) & 5.31 \\
\hline \multicolumn{7}{|l|}{ Session 2} \\
\hline Partner matching & $11.19(4)$ & $11.35(5)$ & $10.00(5)$ & $8.94(4)$ & $9.85(5)$ & 10.28 \\
\hline Random matching & $0.25(1)$ & N/A (0) & N/A (0) & $0.50(1)$ & N/A (0) & 0.38 \\
\hline \multicolumn{7}{|l|}{ Session 3} \\
\hline Partner matching & $10.80(5)$ & $9.45(5)$ & $6.08(3)$ & $8.25(4)$ & $9.50(4)$ & 9.07 \\
\hline Random matching & N/A (0) & N/A (0) & $2.75(2)$ & $2.00(1)$ & $0.75(1)$ & 2.06 \\
\hline \multicolumn{7}{|l|}{ Average } \\
\hline Partner matching & $10.97(15)$ & $10.25(15)$ & $8.57(11)$ & $7.77(14)$ & $8.20(15)$ & 9.20 \\
\hline Random matching & $0.25(1)$ & $4.75(1)$ & $4.40(5)$ & $1.25(2)$ & $0.75(1)$ & 3.03 \\
\hline \multicolumn{7}{|c|}{ (b) The ENDO-M treatment } \\
\hline \multicolumn{7}{|c|}{ Session 7} \\
\hline Partner matching & $12.44(4)$ & $9.44(4)$ & $6.83(3)$ & $6.42(3)$ & $7.00(3)$ & 8.72 \\
\hline Random matching & $9.00(1)$ & $3.25(1)$ & $5.88(2)$ & $11.25(2)$ & $6.00(2)$ & 7.31 \\
\hline \multicolumn{7}{|l|}{ Session 8} \\
\hline Partner matching & $11.50(5)$ & $11.25(4)$ & $9.06(4)$ & $12.17(3)$ & $10.31(4)$ & 10.83 \\
\hline Random matching & N/A (0) & $7.75(1)$ & $4.75(1)$ & $4.75(2)$ & $1.25(1)$ & 4.65 \\
\hline \multicolumn{7}{|l|}{ Session 9} \\
\hline Partner matching & $13.29(6)$ & $11.20(5)$ & $10.42(6)$ & $9.31(4)$ & $9.40(5)$ & 10.87 \\
\hline Random matching & N/A (0) & $6.50(1)$ & N/A (0) & $8.75(2)$ & $5.00(1)$ & 7.25 \\
\hline \multicolumn{7}{|l|}{ Average } \\
\hline Partner matching & $12.47(15)$ & $10.67(13)$ & $9.17(13)$ & $9.30(10)$ & $9.10(12)$ & 10.27 \\
\hline Random matching & $9.00(1)$ & $5.83(3)$ & $5.50(3)$ & $8.25(6)$ & $4.56(4)$ & 6.51 \\
\hline \multicolumn{7}{|c|}{$\begin{array}{l}\text { (c) The EXO treatment (partner match- } \\
\text { ing) }\end{array}$} \\
\hline Session 4 & $8.29(6)$ & $8.42(6)$ & $7.54(6)$ & $7.96(6)$ & $6.67(6)$ & $7.78(6)$ \\
\hline Session 5 & $9.58(6)$ & $6.83(6)$ & $6.42(6)$ & $5.67(6)$ & $6.17(6)$ & $6.93(6)$ \\
\hline Session 6 & $9.80(5)$ & $9.50(5)$ & $8.10(5)$ & $6.80(5)$ & $7.55(5)$ & $8.35(5)$ \\
\hline Average & $9.19(17)$ & $8.18(17)$ & $7.31(17)$ & $6.81(17)$ & $6.75(17)$ & $7.65(17)$ \\
\hline
\end{tabular}

The numbers in parentheses are the numbers of groups that operated in the regime in the first column of the corresponding row. The average contributions were calculated using subjects' round 1 behaviors in each supergame and session 
Subjects' contribution amounts were very different between groups that selected the partner matching protocol and those that selected the random matching protocol. The average contribution for the latter was significantly lower than for the former (Table 2). ${ }^{28}$ This finding is consistent with Summary $3 .^{29}$

Result 2 (i) Regardless of which voting rule was used, subjects contributed significantly more when they democratically implemented the partner matching protocol, compared with when they were exogenously given the same matching protocol. This difference remained similar from the first to the last supergame. (ii) The impact of democracy is stronger under the majority rule than under the unanimity rule. (iii) Subjects contributed significantly more in the partner matching than in the random matching protocol.

These results are robust even if we consider the possibility of small selection effects. For instance, as discussed with Table 1, one group selected the random matching protocol in the 1st supergame in each of the ENDO-U and ENDO-M treatments. One might assume that the least cooperative groups selected the random matching protocol and thus the effect of democracy seen in Tables 2 and 3 may be overestimated. As a robustness check, I conducted two further regressions with specifications the same as those in columns (1) and (4) of Table 3, while excluding one group with the lowest contribution amount in the EXO treatment. As shown in Appendix Table C.4, it was found that the Endo dummy variable has a significantly positive coefficient as in columns (1) and (4) of Table 3. I likewise conducted a robustness check for the results of columns (2) and (5) by dropping groups with the lowest contribution amounts in other supergames of the EXO treatment and found that the Endo dummy still obtains a significant coefficient (the details are included in Appendix Table C.4).

Result 2 (iv) Results 2(i) and (ii) are not due to possible selection effects.

As shown in Part I of Appendix Table C.1, some groups did not unanimously agree on one of the two protocols even in the last voting stage (i.e., the 20th voting stage). Results in Table 3 change little even if we exclude these groups from regressions in the ENDO-U treatment (see Appendix Table C.3 for the estimation results).

\footnotetext{
${ }^{28}$ We compared the average contributions between the two matching protocols using data from all supergames considering Result 1(i). Tobit regressions with standard errors clustered by session ID find that the differences are significant at $p=0.017(p=0.041)$ and $p=0.065(p=0.002)$ when only data in round 1 (data in all rounds) are used in the ENDO-U and ENDO-M treatments, respectively. Recall that most groups selected the partner matching protocol. Although we cannot rule out the effect of selection bias, this estimation result suggests that subjects who selected random matching may have believed that more than one group selected that matching option and have acted differently from under the partner matching protocol.

${ }^{29}$ As an anonymous referee pointed out, another possible experimental design could be to let subjects play the game under the partner matching or random matching before making a voting decision, because some subjects may not appreciate beforehand the beneficial effects of having fixed partners. Result 1(i), however, implies that such experiences are not necessary for subjects to select the partner matching protocol.
} 


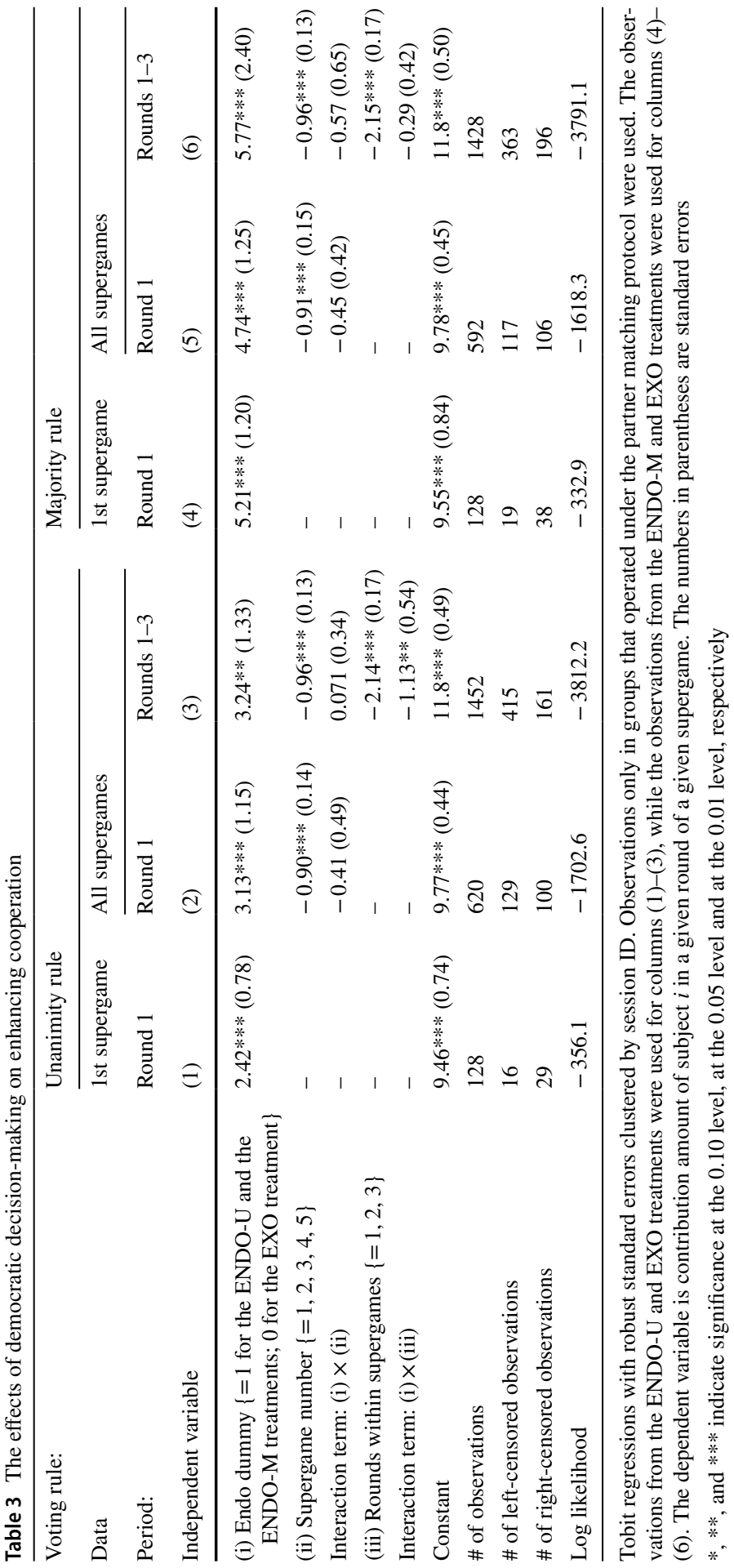


A question not answered so far by relying on empirical strategies $a$ and $b$ is how the impact of democracy transits within the supergames. One advantage of the experimental design was that subjects interact repeatedly within supergames. This design feature may enable us to address this additional question. Although not all groups played more than one round in each supergame, on average over half of groups did go through three rounds within supergames. ${ }^{30}$ Specifically, on average $78.4 \%, 64.7 \%, 48.2 \%$, and only $30.3 \%$ of groups reached round 2 , round 3 , round 4 and round 5, respectively, as outcomes of random draws in the continuation rule. Hence, I study the persistence of the impact of democracy using data from the first three rounds within supergames. ${ }^{31}$

I employ a method to perform a regression analysis as in Table 3 with the same specifications just studied based on strategies $a$ and $b$, except that the Rounds within supergames variable and its interaction with the Endo dummy are additionally included as independent variables [columns (3) and (6) of Table 3]. First, the estimation results show that the Rounds within supergames variable has a significantly negative coefficient. This is natural because an instance of defection usually spreads across the group over time as some subjects act according to conditional cooperation or punishment strategies in infinitely repeated game interactions (e.g., Camera and Casari 2009; Kamei 2017). Note that subjects must withhold cooperation in my design to punish uncooperative partners because they do not have another punishment stage. Second, and more importantly, the additional interaction term has a significantly negative coefficient when the unanimity rule is used, whereas it does not when the majority rule is used. This suggests that the premium from endogenous adoption of partner matching diminishes from round to round under the unanimity rule, but it persists over the rounds under the majority rule. This result strengthens Result 2(ii).

Result 3 Despite Result 2(i), the within-supergame trend for the impact of democracy differs by voting rule. Specifically, the positive impact persists over rounds under the majority rule, but diminishes from round to round under the unanimity rule in a given supergame.

\subsection{Subjects' beliefs on their peers' action choices}

A possible underlying factor that may be driving Result 2 is the effect of democratic decision-making on enhancing beliefs as to peers' cooperation behaviors. This effect stems from two potential sources: the effect of voting as an indirect signal of

\footnotetext{
${ }^{30}$ We cannot compare within-supergame trends between the ENDO-U or ENDO-M treatment and the EXO treatment by only using the data from the first supergame, because in the EXO treatment the supergame lengths were one round for two sessions and two rounds for the other session in that supergame.

31 Although the number of observations increases if we use data up to round 4, we then require greater reliance on a subset of groups (on average a little over $50 \%$ of groups did not reach round 4 ). Nevertheless we note that results I will present now little change even when we use data up to round 4 within supergames.
} 
cooperation (e.g., Tyran and Feld 2006) and the direct effect that democracy has on people's beliefs (a democracy premium).

I first studied how subjects' beliefs evolved from supergame to supergame (Table 4). The average beliefs in the 1st supergame formed by subjects who implemented the partner matching protocol in the ENDO-U and ENDO-M treatments were higher than those formed by subjects who were exogenously given the same protocol in the EXO treatment. The differences are significant (see columns (1) and (3) in Table 5 and Table C.5). This is suggestive of the idea that democratic decision-making positively affects people's beliefs. ${ }^{32}$ On the other hand, average beliefs under the partner matching protocol in the ENDO-U treatment declined rapidly from supergame to supergame, and settled at a similar level to the EXO treatment in the 3rd to 5th supergames (see again Table 4). A regression analysis indicates that the average beliefs across all supergames are at most weakly significantly different between the ENDO-U and EXO treatments when partner matching is in effect (column (2), Table 5) ${ }^{33}$ This rapid decline of beliefs in the ENDO-U treatment is in contrast with subjects' action choices: subjects' average contribution amounts did not decline very quickly with the democratic decision process (Table 2). In the ENDO-M treatment, although the average beliefs were always higher than those in the EXO treatment (Table 4), the former is not significantly different from the latter according to a regression analysis due to high variation [column (4), Table 5]. This is in contrast with subjects' strong contribution behaviors displayed in the ENDO-M treatment [columns (4) to (6) in Table 3]. These observations on beliefs and action choices provide tentative evidence that democratic decision-making itself have directly affected the subjects' contribution behavior via a channel other than beliefs (e.g., Dal Bó et al. 2010; Kamei 2016).

In order to formally explore the role of subjects' beliefs on their decisions to contribute, I conducted regressions that included subjects' beliefs as an additional independent variable in the same specifications as Table 3. In this analysis, I further added the interaction term between the belief variable and the Endo dummy variable as an independent variable to analyze how the correlation between subject's own

\footnotetext{
32 As an anonymous referee pointed out, this result may have been caused by two possibilities: (a) voting for the partner matching protocol raises subjects' beliefs, or (b) merely optimistic subjects vote for the partner matching option. To exclude possibility (b), I calculated the fraction of subjects who believed that peers contributed more than ten points or contributed the full endowment ( 20 points), out of the total number of subjects in a given treatment, not out of the number of subjects under partner matching. The fractions of those who believed peers' contribution of more than ten points (20 points) were $34.38 \%$ $(14.06 \%), 43.75 \%(18.75 \%)$ and $26.47 \%(7.35 \%)$ in the ENDO-U, ENDO-M and EXO treatments, respectively. These calculations are consistent with the pattern that possibility (a) implies. The difference in the fraction of those who believed their peers' contribution to be more than ten points (20 points) is significant at two-sided $p=0.0373$ (0.0507) in the ENDO-M treatment, while it is not significant in the ENDO-U treatment. This suggests that the impact of factor (a) is stronger in the ENDO-M than in the ENDO-U treatment, which is consistent with other analyses which will be reported in Sect. 4.5.

33 This weak significant result is not robust. The Endo dummy fails to obtain a significant coefficient if an ordered probit regression model is used. The average beliefs across all the supergames are also not significantly different between the ENDO-U and EXO treatments according to two-sided Mann-Whitney tests $(p$ value $=0.2752)$.
} 
Table 4 Beliefs on matched partners' average contribution amounts in each supergame

\begin{tabular}{|c|c|c|c|c|c|c|}
\hline & 1 st SG & 2nd SG & 3rd SG & 4th SG & 5th SG & All supergames \\
\hline \multicolumn{7}{|c|}{ (a) The ENDO-U treatment } \\
\hline \multicolumn{7}{|l|}{ Session 1} \\
\hline Partner matching & $11.63(6)$ & $11.10(5)$ & $7.58(3)$ & $6.92(6)$ & $6.83(6)$ & 8.87 \\
\hline Random matching & N/A (0) & $7.75(1)$ & $4.58(3)$ & N/A (0) & N/A (0) & 5.38 \\
\hline \multicolumn{7}{|l|}{ Session 2} \\
\hline Partner matching & $10.25(4)$ & $8.40(5)$ & $7.10(5)$ & $6.00(4)$ & $6.50(5)$ & 7.61 \\
\hline Random matching & $3.25(1)$ & N/A (0) & N/A (0) & $0.75(1)$ & N/A (0) & 2.00 \\
\hline \multicolumn{7}{|l|}{ Session 3} \\
\hline Partner matching & $11.15(5)$ & $10.90(5)$ & $7.75(3)$ & $7.44(4)$ & $7.44(4)$ & 9.10 \\
\hline Random matching & N/A (0) & N/A (0) & $8.13(2)$ & $2.75(1)$ & $2.75(1)$ & 5.44 \\
\hline \multicolumn{7}{|l|}{ Average } \\
\hline Partner matching & $11.10(15)$ & $10.13(15)$ & $7.41(11)$ & $6.80(14)$ & $6.88(15)$ & 8.57 \\
\hline Random matching & $3.25(1)$ & $7.75(1)$ & $6.00(5)$ & $1.75(2)$ & $2.75(1)$ & 4.34 \\
\hline \multicolumn{7}{|c|}{ (b) The ENDO-M treatment } \\
\hline \multicolumn{7}{|l|}{ Session 7} \\
\hline Partner matching & $10.00(4)$ & $8.44(4)$ & $8.33(3)$ & $6.83(3)$ & $7.58(3)$ & 8.35 \\
\hline Random matching & $5.00(1)$ & $7.25(1)$ & $4.63(2)$ & $9.38(2)$ & $5.88(2)$ & 6.50 \\
\hline \multicolumn{7}{|l|}{ Session 8} \\
\hline Partner matching & $11.65(5)$ & $10.88(4)$ & $10.13(4)$ & $8.58(3)$ & $10.88(4)$ & 10.58 \\
\hline Random matching & N/A (0) & $8.25(1)$ & $5.00(1)$ & $6.88(2)$ & $2.50(1)$ & 5.90 \\
\hline \multicolumn{7}{|l|}{ Session 9} \\
\hline Partner matching & $13.42(6)$ & $12.1(5)$ & $9.92(6)$ & $8.25(4)$ & $6.50(5)$ & 10.23 \\
\hline Random matching & N/A (0) & $5.25(1)$ & N/A (0) & $7.25(2)$ & $8.75(1)$ & 7.13 \\
\hline \multicolumn{7}{|l|}{ Average } \\
\hline Partner matching & $11.72(15)$ & $10.30(13)$ & $9.47(13)$ & $8.36(10)$ & $8.27(12)$ & 9.67 \\
\hline Random matching & $6.00(1)$ & $7.40(3)$ & $6.30(3)$ & $6.39(6)$ & $6.50(4)$ & 6.47 \\
\hline \multicolumn{7}{|c|}{ (c) The EXO treatment (partner matching) } \\
\hline Session 4 & $9.63(6)$ & 9.67 (6) & $8.04(6)$ & $6.67(6)$ & $7.29(6)$ & 8.26 \\
\hline Session 5 & $8.83(6)$ & $8.17(6)$ & $7.67(6)$ & $4.46(6)$ & $4.58(6)$ & 6.74 \\
\hline Session 6 & $11.10(5)$ & $9.40(5)$ & $8.35(5)$ & $8.50(5)$ & $6.60(5)$ & 8.79 \\
\hline Average & $9.78(17)$ & $9.06(17)$ & $8.00(17)$ & $6.43(17)$ & $6.13(17)$ & 7.88 \\
\hline
\end{tabular}

The numbers in parentheses are the numbers of groups that operated in the regime in the first column of the corresponding row as a result of voting

contribution amounts and beliefs differ by the presence of the democratic decision process. Two interesting patterns were found. First, as shown in Table 6, the Endo dummy either no longer obtains a significant coefficient or has a much smaller point estimate (even if significant), once the beliefs are controlled for. The variable for subjects' beliefs obtains a significantly positive coefficient in every specification. This implies that one driver for the highly significant impact of democracy seen in Result 2 could be subjects' more optimistic beliefs in the ENDO-U and ENDO-M treatments than in the EXO treatment. Second, democracy directly affects subjects' 
Table 5 The effects of democratic decision-making on the formation of subjects' beliefs

\begin{tabular}{|c|c|c|c|c|}
\hline \multirow{3}{*}{$\begin{array}{l}\text { Voting rule } \\
\text { Data } \\
\text { Independent variable }\end{array}$} & \multicolumn{2}{|l|}{ Unanimity rule } & \multicolumn{2}{|l|}{ Majority rule } \\
\hline & 1st supergame & All supergames & 1st supergame & All supergames \\
\hline & (1) & (2) & (3) & (4) \\
\hline $\begin{array}{l}\text { (i) Endo dummy }\{=1 \text { for the } \\
\text { ENDO-U and ENDO-M treat- } \\
\text { ments; } 0 \text { for the EXO treatment }\}\end{array}$ & $\begin{array}{l}1.61^{* *} \\
(0.74)\end{array}$ & $\begin{array}{l}1.40 * \\
(0.77)\end{array}$ & $\begin{array}{l}2.59^{*} \\
(1.41)\end{array}$ & $\begin{array}{l}2.14 \\
(1.81)\end{array}$ \\
\hline $\begin{array}{l}\text { (ii) Supergame number }\{=1,2,3 \text {, } \\
4,5\}\end{array}$ & - & $\begin{array}{c}-1.03^{* * * *} \\
(0.14)\end{array}$ & - & $\begin{aligned}-1.04 \\
(0.14)\end{aligned}$ \\
\hline Interaction term: $(\mathrm{i}) \times(\mathrm{ii})$ & - & $\begin{array}{l}-0.24 \\
(0.17)\end{array}$ & - & $\begin{array}{r}-0.064 \\
(0.53)\end{array}$ \\
\hline Constant & $\begin{array}{r}9.85^{* * * *} \\
(0.66)\end{array}$ & $\begin{array}{r}11.0^{* * *} \\
(0.37)\end{array}$ & $\begin{array}{r}9.86^{* * * *} \\
(0.67)\end{array}$ & $\begin{array}{r}11.0^{* * * *} \\
(0.38)\end{array}$ \\
\hline \# of observations & 128 & 620 & 128 & 592 \\
\hline \# of left-censored observations & 4 & 22 & 5 & 21 \\
\hline \# of right-censored observations & 14 & 23 & 17 & 34 \\
\hline Log pseudo likelihood & -373.5 & -1764.6 & -372.1 & -1719.5 \\
\hline
\end{tabular}

Dependent variable: Subject $i$ 's belief on his or her three interaction partners' average contribution amount in a given supergame

Tobit regressions with robust standard errors clustered by session ID. As for the ENDO-U and ENDO$\mathrm{M}$ treatments, only observations in groups which selected the partner matching protocol were used. The numbers in parentheses are standard errors

As a robustness check, I also conducted individual random-effects ordered probit regressions with standard errors clustered by session ID. The Endo dummies in the specification of columns (1) and (3) both obtain significantly positive coefficients at the $5 \%$ level. The Endo dummies in the specifications of columns (2) and (4) both fail to obtain significant coefficients. The results are included in Appendix Table C.5

$*, * *$, and $* * *$ indicate significance at the 0.10 level, at the 0.05 level and at the 0.01 level, respectively

contribution behaviors positively through a channel other than beliefs in the ENDO$\mathrm{M}$ treatment, the treatment with the stronger effect of democratic decision-making, as indicated by the positive and significant coefficient on the Endo dummy [see column (6)]. ${ }^{34}$

Result 4 (i) Beliefs on interaction peers' contribution amounts formed by subjects who implemented the partner matching protocol in the ENDO-U and ENDO-M treatments were significantly higher than those formed by subjects who were given the same protocol in the EXO treatment in the 1st supergame. (ii) Result 2(i) was partly caused by subjects' beliefs enhanced by the endogenous adoption of partner matching. However, (iii) democracy also directly affected subjects' contribution behaviors through channels other than beliefs, particularly in the ENDO-M treatment.

\footnotetext{
${ }^{34}$ Whether this holds also for the ENDO-U treatment is ambiguous because while the Endo dummy has a significantly positive coefficient in column (3), the interaction term between the Endo dummy and the belief variable has a significantly negative coefficient.
} 


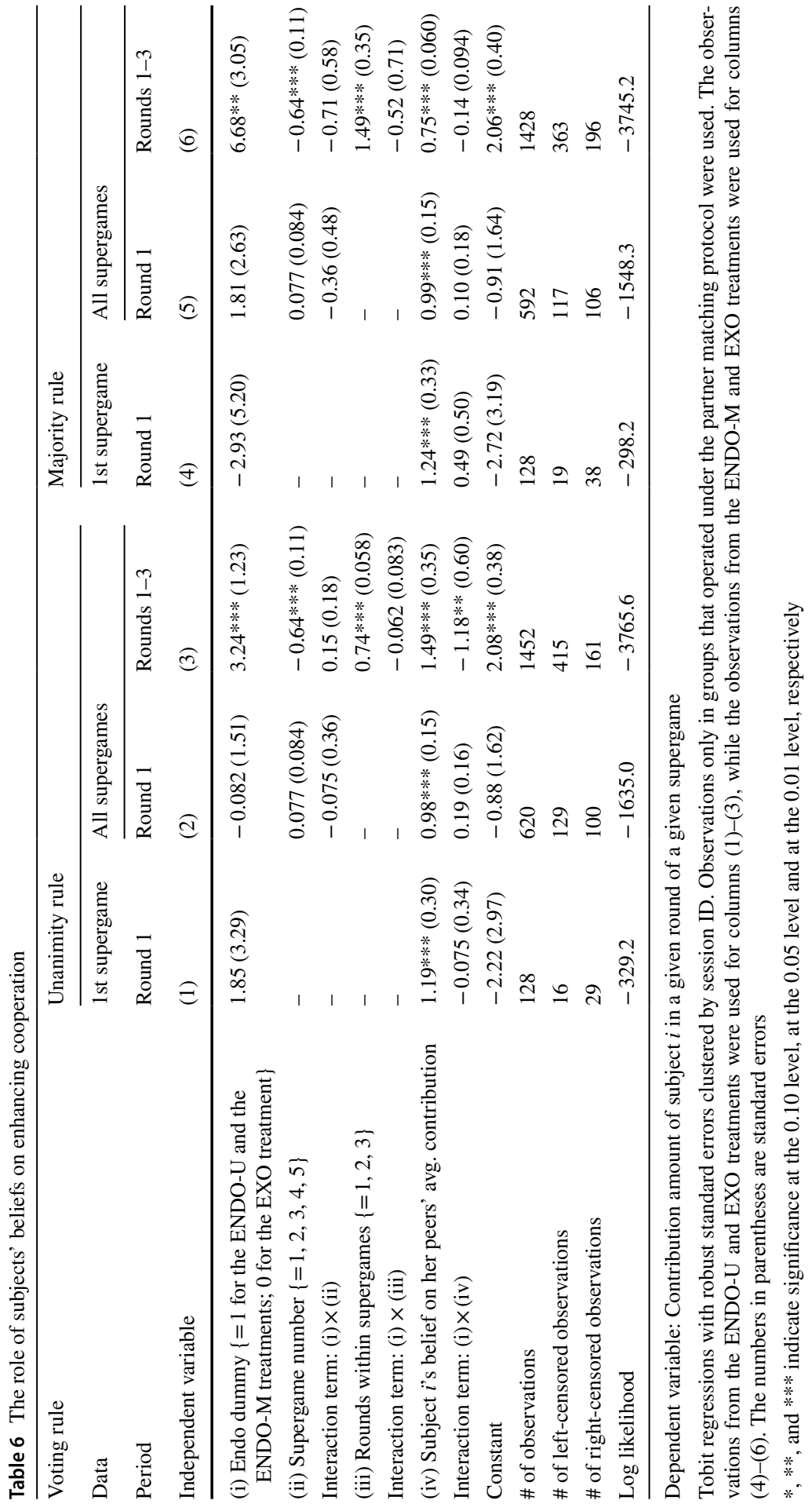


As is usually the case in this kind of study, we cannot disentangle the effects on beliefs [Result 4(ii)] into signaling effects and democracy premiums. Nevertheless, Result 4(iii) suggests that democracy premiums should be part of the story that accounts for Result 2 in the ENDO-M treatment.

\subsection{The process to implement the partner matching protocol and subjects' contribution behavior}

As mentioned earlier, the number of voting stages required to reach a consensus in the ENDO-U treatment, as well as the number of supporters for the partner matching protocol ("Y-voter," hereafter) in the ENDO-M treatment, differed by group [Result 1(ii)]. In Sect. 4.4, I explore how the differences in agreement pattern affected subjects' belief formation and action choices.

Figure 2 reports the average contributions and beliefs under the partner matching protocol by the number of voting stages spent in the ENDO-U treatment, or by the number of the Y-voters in the ENDO-M treatment. ${ }^{35}$ Two clear patterns were found regarding subjects' contribution behaviors. First, subjects' contribution amounts in the ENDO-U treatment were clearly higher when they underwent a small number of voting stages to reach a consensus, compared with subjects in the EXO treatment [Panel I(a)]. They contributed much less, however, when they instead had to undergo all 20 voting stages, compared with subjects in the EXO treatment. Second, the higher number of supports a group had for implementing the partner matching protocol in the ENDO-M treatment, the higher average contribution they achieved [Panel II(a)]. Especially, when all four members supported the partner matching protocol, the average contributions were $58.6 \%$ and $60.3 \%$ higher than those in the EXO treatment in the 1st SG data and All SG data, respectively. These differences are statistically significant at the $1 \%$ level. Notice, however, that the differences in the average contribution between the ENDO-M and EXO treatments drastically shrink when not all members vote for the partner matching protocol. Nevertheless, the average contributions in the ENDO-M treatment never become lower than those in the EXO treatment, unlike in the ENDOU treatment.

Result 5 (i) The smaller the number of voting stages that a group underwent to achieve a consensus, the larger the average contribution that the group achieved in the ENDO-U treatment. (ii) The higher the number of supports a group had when implementing the partner matching protocol, the higher the average contribution that the group achieved in the ENDO-M treatment.

Subjects' beliefs are reported in Panels (b) of Fig. 2. It first indicates that in the ENDO-U treatment, regardless of the number of voting stages to reach a consensus,

\footnotetext{
35 See Supplementary Appendix Table C.6 for the statistical tests that check whether the differences between the ENDO-U or ENDO-M treatment and the EXO treatment are significant.
} 


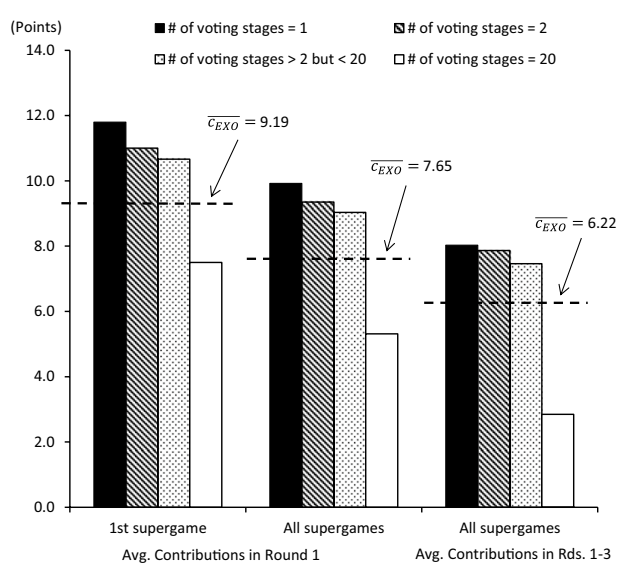

(a) Average contribution amounts

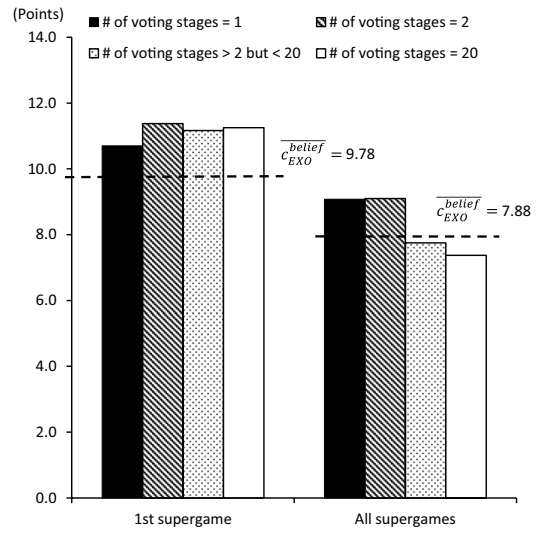

(b) Average beliefs

(I) Average Data in the ENDO-U Treatment by the Number of Voting Stages Required to Reach a Consensus

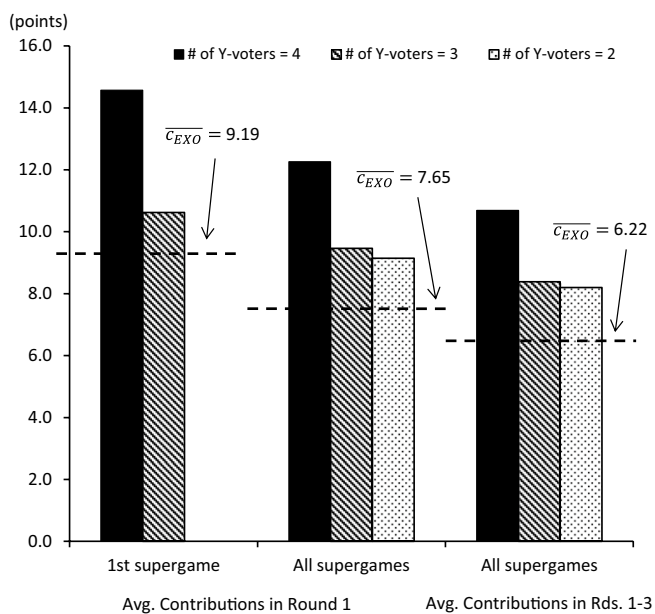

(a) Average contribution amounts ${ }^{\# 1}$

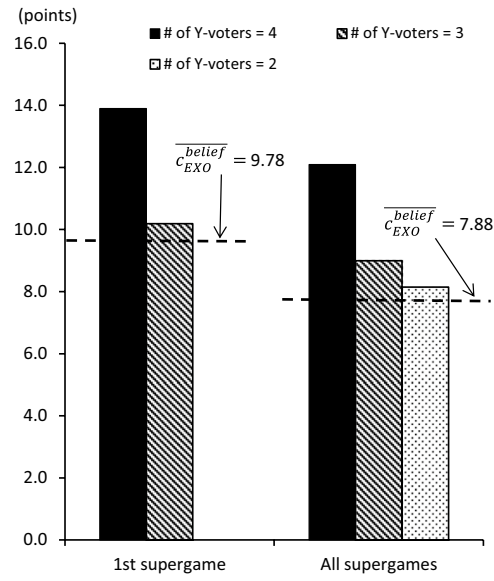

(b) Average beliefs

(II) Average Data in the ENDO-M Treatment by the Number of Y-Voters

Fig. 2 Average contributions and beliefs under the partner matching protocol by the voting pattern. Notes: $\overline{c_{E X O}}\left(\overline{c_{E X O}^{\text {belief }}}\right)$ is the average contribution (average belief) in the EXO treatment in panel a (panel b). ${ }^{\# 1}$ There are zero cases in which the number of supports was two and the computer randomly implemented the partner matching protocol in the first supergame

democratic decision-making enhances subjects' beliefs in the first supergame. This suggests that the impact of voting on beliefs was present, regardless of the duration of voting, under the unanimity rule. Recall, however, that subjects in groups that underwent the full set of voting stages contributed much less (panel I(a) in Fig. 2). This implies that the democratic decision process alone is not enough to persuade 


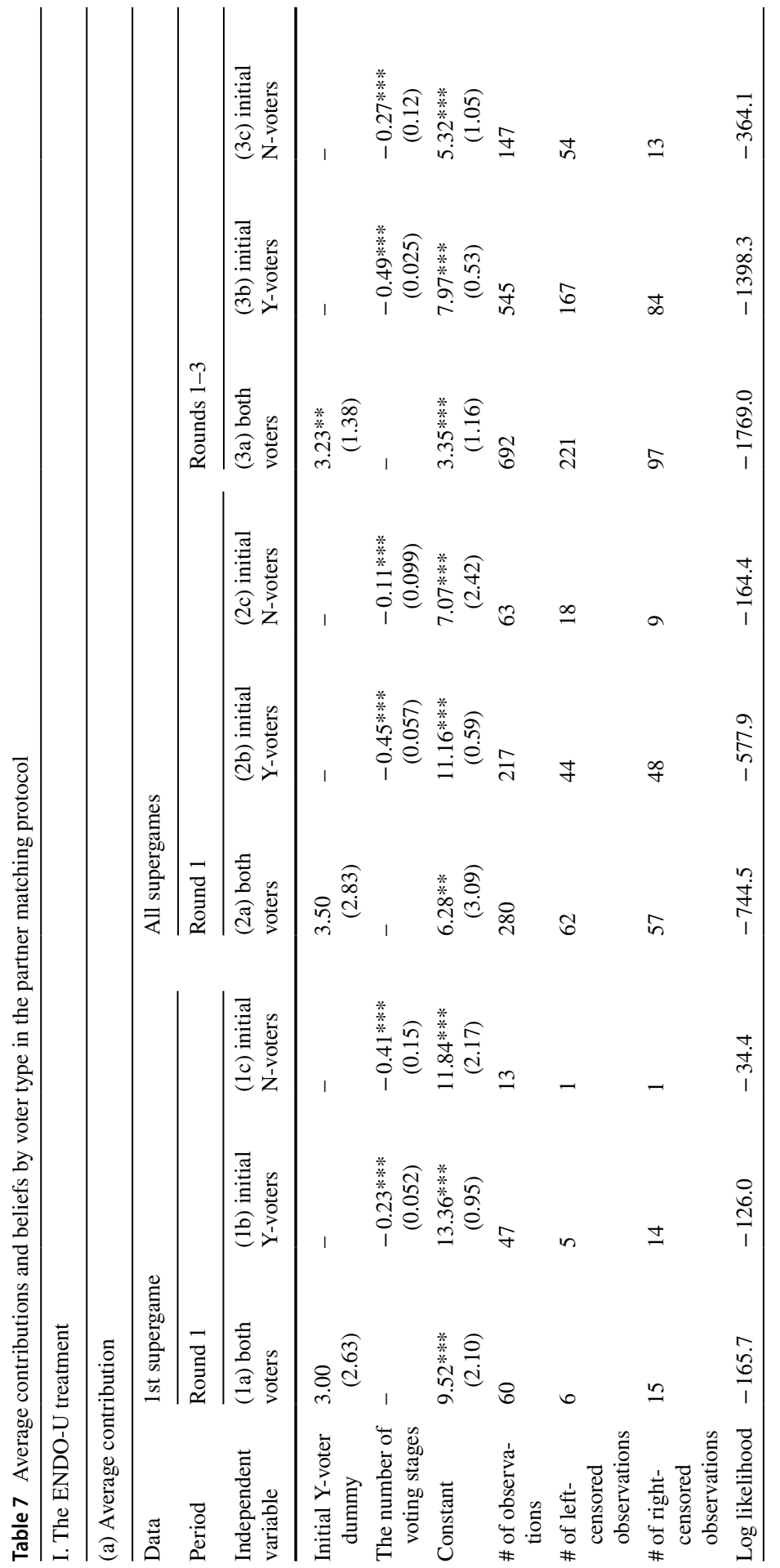




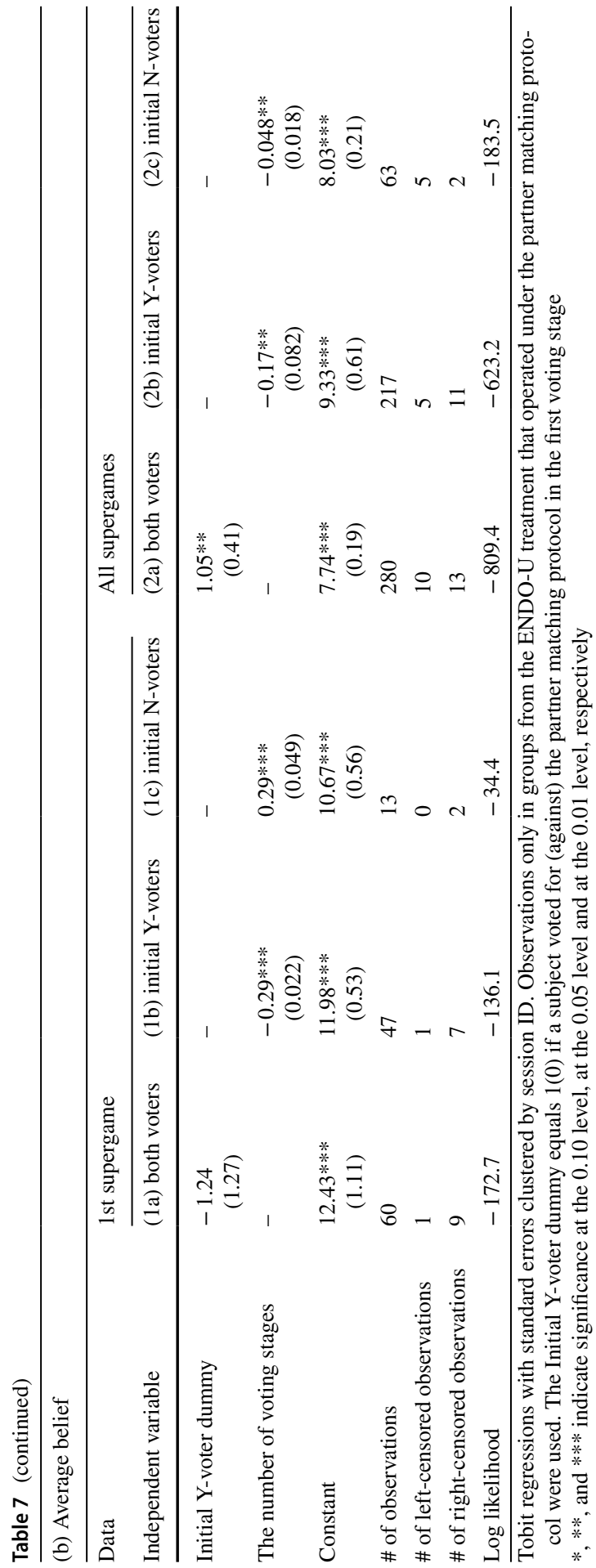




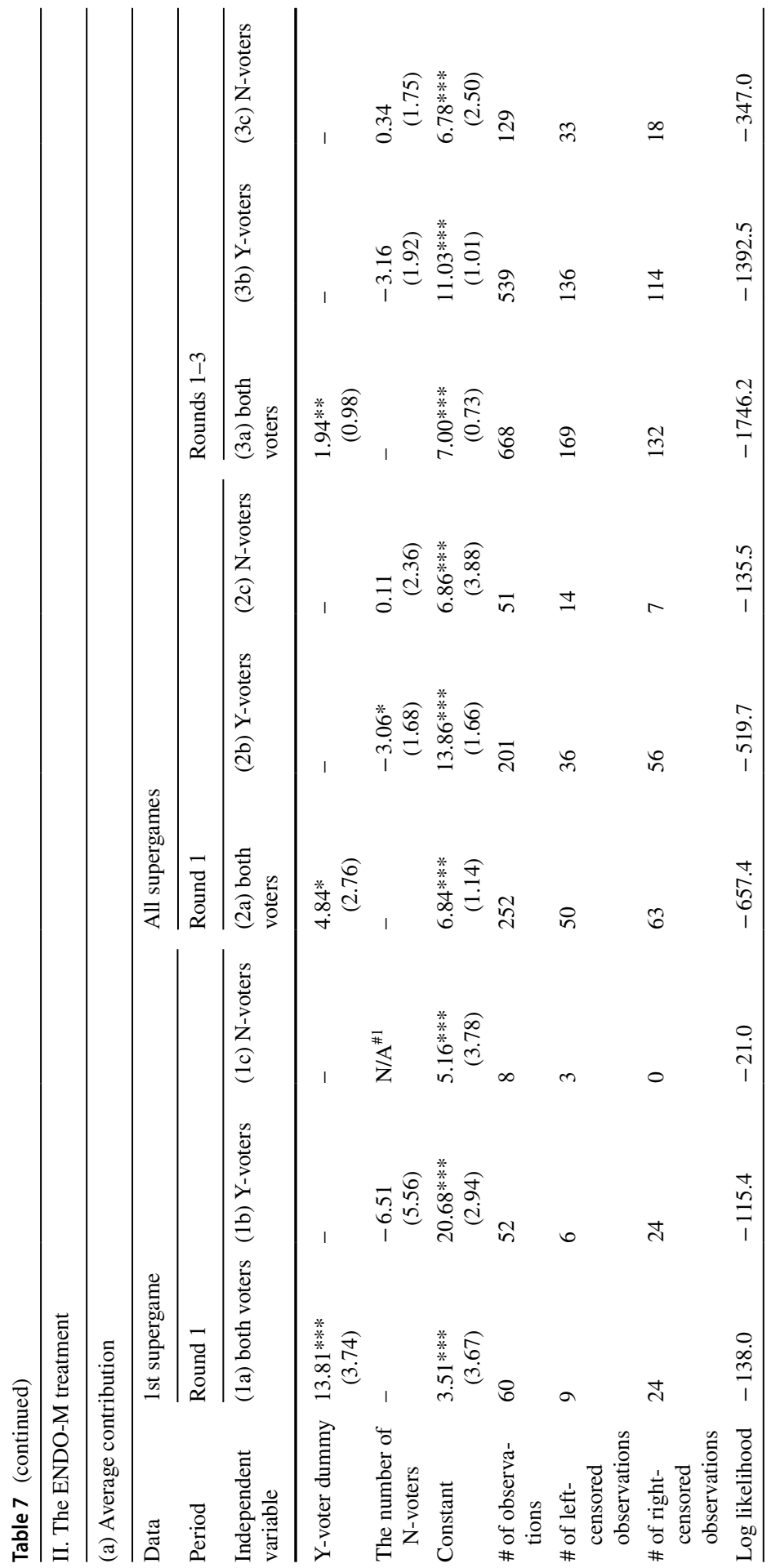




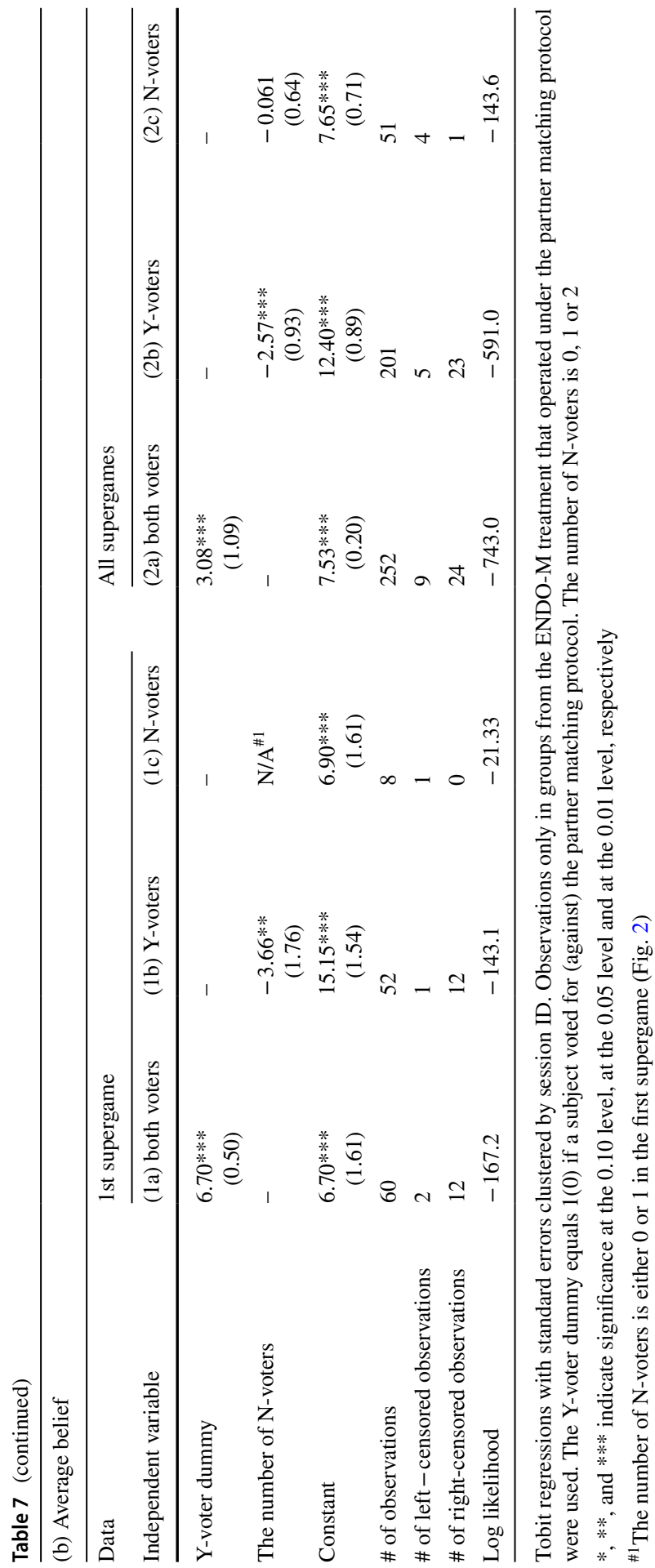


some very uncooperative subjects to cooperate. The result is similar to Dal Bó et al. (2010) and Kamei (2016) where majority rules were used. In Dal Bó et al. (2010) and Kamei (2016), only supporters of a policy exhibited the positive effects from democratic decision-making. If we use data from all supergames, we observed positive correlations between subjects' beliefs and the numbers of voting stages spent on implementing the partner matching protocol [see again Panel I(b)].

Second, in the ENDO-M treatment, the patterns of subjects' beliefs are almost the same as those of their contribution behaviors in both the data from the first supergame and from all supergames. These patterns seem to imply that voting has a stronger functioning for a cooperative subject to send a signal of future cooperation in the ENDO-M than in the ENDO-U treatment.

Result 6 (i) Democratic decision-making enhanced subjects' beliefs, regardless of how many voting stages they underwent for an agreement, in the first supergame in the ENDO-U treatment. (ii) The higher number of Y-voters a group had, the more likely group members believed that their peers were to contribute large amounts in the ENDO-M treatment.

\subsection{Subjects' belief formation and decision to contribute by the voter type}

We found that the impact of democracy is stronger when the majority rule, rather than the unanimity rule, is applied [Result 2(ii) and Result 3]. Lastly, I will explore possible causes for this result by studying how subjects' voting preferences and the voting patterns in the group are linked to their decisions to contribute.

In the ENDO-U treatment, subjects continued to vote until they reached a consensus. I first classified subjects into those who voted for or against the partner matching protocol in the first voting stage ("initial Y-voters" and "initial N-voters," hereafter), and then investigated how the duration of voting stages affected their belief formation and decisions to contribute under the partner matching (Panel I of Table 7). Two interesting patterns were found. First, the initial Y-voters on average contributed larger amounts than the initial N-voters did, but the difference is not significant when we use the round 1 behaviors in the 1 st SG or all SG data [columns (1a) and (2a) in Panel I(a)]. In addition, the beliefs formed by the initial Y-voters are not significantly different from those by the initial $\mathrm{N}$-voters in the first supergame [column (1a) in Panel I(b)] This seem to suggest that initial votes casted by subjects were not precise indicators of subjects' willingness to contribute. This also implies that voters' signaling effects may have been weak in the ENDO-U treatment. ${ }^{36}$ Second,

\footnotetext{
${ }^{36}$ As an anonymous referee pointed out, the unanimity rule in that all voters must agree on one matching option by repeated voting may have made subjects behave strategically, as has been shown in jury decisions to convict (Guarnaschelli et al. 2000) or in voter turnout decisions in election (Battaglini et al. 2010). Possible strategic voting may partly account for these small differences in behaviors between the initial Y-voters and the initial N-voters and also for Results 2(ii) and 3.
} 
the larger number of voting stages that a subject went through, the smaller amounts she believed that their peers would contribute and the smaller amounts she herself contributed to the public account. ${ }^{37}$ This holds, regardless of whether a subject is an initial Y-voter or an initial N-voter, except for the belief formation by the initial $\mathrm{N}$-voters in the 1 st supergame. ${ }^{38}$ The effects are strong in all specifications. This suggests that subjects interpret a short (long) duration of voting stage as their peers' high (low) willingness to contribute.

Result 7 (i) The larger number of voting stages a subject experienced in the ENDOU treatment, the smaller amounts she believed that their peers would contribute and the smaller amounts she herself contributed.

Subjects cast votes once in each supergame in the ENDO-M treatment. I denote subjects who voted against the partner matching protocol (those who are not Y-voters) as the "N-voters." Two clear patterns were found (Panel II of Table 7). First, the Y-voters contributed by far larger amounts than N-voters did [Panel II(a)]. This suggests that unlike the ENDO-U treatment, subjects' votes in the ENDO-M treatment were clearly linked to their decisions to contribute and thus were presumably clear signals of their inclinations to cooperate. This interpretation can also be seen in the data from beliefs. The Y-voters formed significantly higher beliefs on the peers' contribution behaviors than the N-voters did, when the partner matching protocol was imposed in accord with their voting [Panel II(b)]. Second, the numbers of N-voters are on average negatively correlated with Y-voters' decisions to contribute. Also, the Y-voters' beliefs are negatively correlated with the number of N-voters in their group. These are similar to Result 7(i), although the correlations are not statistically significant for the majority of the specifications.

Result 7 (ii) The Y-voters formed much higher beliefs regarding the peers' contribution behaviors and then contributed significantly more than the N-voters did under partner matching in the ENDO-M treatment.

As discussed in Result 1(i), the partner matching protocol received overwhelming supports from the first supergame. Nevertheless, subjects' experiences in the previous supergame may make subjects re-consider which matching protocol to vote for in a given supergame. If subjects cast more honest preferences in voting in the ENDO-M than in the ENDO-U treatment, the past experiences may affect their

\footnotetext{
${ }^{37}$ I also conducted the same regression while controlling for the ratio of the average realized group contribution to $i$ 's belief in the previous supergame. To include the recent experience variable as an independent variable, I restricted data to observations after the first supergame where groups operated under the partner matching protocol for two adjacent supergames. Although the number of available data diminishes, the number of voting stages has a significantly negative coefficient for the initial Y-voters' decisions to contribute at the $1 \%$ level.

38 The number of voting stages has a significantly positive coefficient for belief formation by the initial $\mathrm{N}$-voters in the 1st supergame (column (1c) in panel $\mathrm{I}(\mathrm{b})$ ). However this probably happened by chance due to small sample. This independent variable has a significantly negative coefficient if we use data from all supergames [column (2c) in panel I(b)].
} 
voting behaviors more strongly in the former than in the latter treatment. As shown in Appendix Table C.7, the data confirm this conjecture. In both of the two endogenous treatments, the higher the average group contribution, relative to her belief, that subject $i$ experienced under partner matching, the more likely that $i$ was to vote for the partner matching protocol in the next supergame; but this relationship is significant only for the ENDO-M treatment.

The pro-cooperation aspect that high credibility of subjects' voting in the ENDO$\mathrm{M}$ treatment produced can also be checked by comparing (a) the groups with four Y-voters in that treatment with (b) the groups with four initial Y-voters in the ENDO-U treatment. As shown in Fig. 2, the former groups had much higher levels of beliefs and then achieved clearly higher levels of contribution than the latter. ${ }^{39}$

In summary, these analyses suggest that Results 2(ii) and 3 can be explained by the difference in subjects' voting behaviors between the ENDO-U and ENDO-M treatments.

\section{Conclusions}

This paper explored whether people collectively prefer to play with each other in a partner matching, rather than a random matching, environment, and whether the democratic selection of the partner matching protocol mitigates subjects' uncooperative behaviors. My experiment, the framework of which is a linear public goods game, provided affirmative answers to both of the questions. First, most groups selected the partner matching protocol from the very first supergame. Second, subjects' levels of contributions were significantly higher when they decided to act under the partner matching protocol by voting than when they were given the same protocol exogenously. The data further indicated that the impact of democracy is not due to selection bias, but could be due to signals sent through voting and/or democracy premiums. The importance of democratic decision-making for beliefs and behavior is similar to recent findings in the experimental literature (e.g. Tyran and Feld 2006; Dal Bó et al. 2010; Kamei 2016; Sutter et al. 2010), and the evidence presented here is the first demonstration in the context of indefinitely repeated situations. The results were robust to the type of voting rule used: the unanimity rule or the majority rule.

Nevertheless, an interesting difference between the two voting rules was also found. The impact of voting on enhancing cooperation was stronger under the majority rule than under the unanimity rule. Moreover, the impact was well sustained under the majority rule, but it diminished from round to round within supergames under the unanimity rule. I acknowledge that there are many other voting

\footnotetext{
39 The differences in average contribution between these two sets of groups are significant at two-sided $p=0.012,0.028$, and 0.001 when round 1 behaviors in the 1 st supergame, and those in all supergames, and rounds 1-3 behaviors in all supergames, respectively, are used, according to tobit regressions. The differences in average belief between these two sets of groups are significant at two-sided $p=0.001$, and 0.002 when beliefs in the 1 st supergame and all supergames, respectively, are used, according to tobit regressions.
} 
rules, such as supermajority rule. How the strength of the democracy effect differs by other voting rule remains an interesting avenue for future research.

Recently Dal Bó et al. (2017) show that voters may make systematic errors by underappreciating peers' responses to a policy when undertaking voting decisions. In their experiment, the majority of subjects voted against levying a tax in a prisoner's dilemma which makes cooperation a dominant strategy, even though the imposition of tax improves overall welfare. ${ }^{40}$ So, why did almost all groups in the present experiment select the partner matching protocol? There is a stark difference in the experimental design between Dal Bó et al. (2017) and my study. While the tax changed both the payoff matrix and the set of equilibria in Dal Bó et al. (2017), subjects in the current study were confronted with the same stage game for two voting options. Thus, arguably, predicting how subjects' behaviors may change by the difference in the matching protocol may not have required high cognitive ability in this experiment. Recall that any symmetric, positive contribution situation is theoretically easier to achieve under the partner matching than under the random matching protocol (Summary 3). The present experimental data in fact revealed that subjects anticipate that their peers would contribute much more in the partner matching than in the random matching, and that the difference between the sizes of subjects' beliefs and realized contributions is small. This implies that subjects may not always underappreciate equilibrium effects.

My experiment is also related to the literature on endogenous regrouping and partner choices. Past experimental studies, using finitely repeated setups, have shown that under certain conditions people improve cooperation in dilemmas if provided with an ability to choose with whom they interact. The findings of my experiment imply that endogenous choices of players per se may partly account for the positive impact of endogenous group formation.

As a final remark, I note that my paper also has a broad implication for experimental research on infinitely repeated dilemma games. Experimental work to investigate the possibility of cooperation is usually designed so that the basic rules of a game, such as continuation probability and matching protocol, are pre-determined without having endogenous features. This paper shows that letting subjects democratically select the partner matching protocol may enhance people's willingness to contribute significantly in indefinitely repeated collective action dilemmas. This implication is that people's behavior and equilibrium selection may be significantly affected by the way in which the basic rules of game are designed (endogenously versus exogenously).

Acknowledgements Funding was provided by the Nakayama Foundation for Human Science (Grant no. research grant for the 2015 year).

OpenAccess This article is distributed under the terms of the Creative Commons Attribution 4.0 International License (http://creativecommons.org/licenses/by/4.0/), which permits unrestricted use, distribution, and reproduction in any medium, provided you give appropriate credit to the original author(s) and the source, provide a link to the Creative Commons license, and indicate if changes were made.

\footnotetext{
${ }^{40}$ In Kamei (2016), 53\% of subjects voted against imposing non-deterrent sanctions even though average contributions were much higher when the sanction policy was imposed than otherwise.
} 


\section{References}

Ahn TK, Isaac M, Salmon T (2008) Coming and going: experiments on endogenous group sizes for excludable public goods. J Public Econ 93(1-2):336-351

Aimone J, Iannaccone L, Makowsky M (2013) Endogenous group formation via unproductive costs. Rev Econ Stud 83:1215-1236

Andreoni J, Miller J (1993) Rational cooperation in the finitely repeated prisoner's dilemma: experimental evidence. Econ J 103:570-585

Battaglini M, Morton R, Palfrey T (2010) The swing voter's curse in the laboratory. Rev Econ Stud 77:61-89

Blume A, Ortmann A (2007) The effects of costless pre-play communication: experimental evidence from games with pareto-ranked equilibria. J Econ Theory 132:274-290

Bock O, Nicklisch A, Baetge I (2014) hroot: Hamburg registration and organization online tool. Eur Econ Rev 71:117-120

Camera G, Casari M (2009) Cooperation among strangers under the shadow of the future. Am Econ Rev 99:979-1005

Charness G, Chun-Lei Y (2014) Starting small toward voluntary formation of efficient large groups in public goods provision. J Econ Behav Organ 102:119-132

Chaudhuri A (2011) Sustaining cooperation in laboratory public goods experiments: a selective survey of the literature. Exp Econ 14:47-83

Cooper R, DeJong D, Forsythe R, Ross Thomas (1992) Communication in coordination games. Q J Econ 107:739-771

Coricelli G, Fehr D, Fellner G (2004) Partner selection in public goods experiments. J Confl Resolut 48(3):356-378

Dal Bó P (2005) Cooperation under the shadow of the future: experimental evidence from infinitely repeated games. Am Econ Rev 95:1591-1604

Dal Bó P, Fréchette G (2011) The evolution of cooperation in infinitely repeated games: experimental evidence. Am Econ Rev 101:411-429

Dal Bó P, Fréchette G (2018) On the determinants of cooperation in infinitely repeated games: a survey. J Econ Lit 56(1):60-114

Dal Bó P, Foster A, Putterman L (2010) Institutions and behavior: experimental evidence on the effects of democracy. Am Econ Rev 100:2205-2229

Dal Bó P, Foster A, Kamei K (2015) The democracy effect: a weights-based identification strategy. Working paper

Dal Bó E, Dal Bó P, Eyster E (2017) The demand for bad policy when voters underappreciate equilibrium effects. Rev Econ Stud 85(2):964-998

Duffy J, Ochs J (2009) Cooperative behavior and the frequency of social interaction. Games Econ Behav $66: 785-812$

Ellison G (1994) Cooperation in the prisoner's dilemma with anonymous random matching. Rev Econ Stud 61:567-588

Fehr E, Gächter S (2000) Cooperation and punishment in public goods experiments. Am Econ Rev 90:980-994

Fehr E, Schurtenberger I (2018) Normative foundations of human cooperation. Nat Hum Behav 2:458-468

Fehr E, Williams T (2018) Social norms, endogenous sorting and the culture of cooperation. Working paper

Feinberg R, Husted T (1993) An experimental test of discount-rate effects on collusive behaviour in duopoly markets. J Ind Econ 41:153-160

Fischbacher U (2007) z-Tree: zurich toolbox for ready-made economic experiments. Exp Econ 10:171-178

Gächter S, Renner E (2010) The effects of (incentivized) belief elicitation in public goods experiments. Exp Econ 13:364-377

Gächter S, Kölle F, Quercia S (2017) Reciprocity and the tragedies of maintaining and providing the commons. Nat Hum Behav 1:650-656

Grimm V, Mengel F (2009) Cooperation in viscous populations-experimental evidence. Games Econ Behav 66:202-220 
Guarnaschelli S, McKelvey R, Palfrey T (2000) An experimental study of jury decision rules. Am Polit Sci Rev 94(2):407-423

Gürerk Ö, Irlenbusch B, Rockenbach B (2006) The competitive advantage of sanctioning institutions. Science 312:108-110

Kamei K (2016) Democracy and resilient pro-social behavioral change: an experimental study. Soc Choice Welf 47:359-378

Kamei K (2017) Endogenous reputation formation under the shadow of the future. J Econ Behav Organ 142:189-204

Kamei K (2018) Promoting competition or helping the less endowed? Distributional preferences and collective institutional choices under intra-group inequality. J Conflict Resolut 62(3):626-655

Kamei K, Putterman L (2017) Play it again: partner choice, reputation building and learning from finitely-repeated dilemma games. Econ J 127(602):1069-1095

Kamei K, Putterman L, Tyran JR (2015) State or nature? Endogenous formal versus informal sanctions in the voluntary provision of public goods. Exp Econ 18(1):38-65

Kandori M (1992) Social norms and community enforcement. Rev Econ Stud 59:63-80

Kreps D, Milgrom P, Roberts J, Wilson R (1982) Rational cooperation in the finitely repeated prisoners' dilemma. J Econ Theory 27:245-252

Ledyard J (1995) Public goods: a survey of experimental research. In: Kagel JH, Roth AE (eds) The handbook of experimental economics. Princeton University Press, Princeton, pp 111-194

Lugovskyy V, Puzzello D, Sorensen A, Walker J, Williams A (2015) An experimental study of finitely and infinitely repeated linear public goods games. Working paper

Markussen T, Putterman L, Tyran JR (2014) Self-organization for collective action: an experimental study of voting on sanction regimes. Rev Econ Stud 81:301-324

Masclet D, Noussair C, Tucker S, Villeval MC (2003) Monetary and non-monetary punishment in the voluntary contributions mechanism. Am Econ Rev 93:366-380

Murnighan K, Roth A (1983) Expecting continued play in prisoner's dilemma games a test of several models. J Confl Resolut 27:279-300

Nicklisch A, Grechenig K, Thöni C (2016) Information-sensitive leviathans. J Public Econ 144:1-13

Page T, Putterman L, Unel B (2005) Voluntary association in public goods experiments: reciprocity, mimicry, and efficiency. Econ J 115(506):1032-1053

Putterman L, Tyran JR, Kamei K (2011) Public goods and voting on formal sanction schemes. J Public Econ 95(9-10): 1213-1222

Roth A, Murnighan K (1978) Equilibrium behavior and repeated play of the prisoner's dilemma. J Math Psychol 17:189-198

Schneider F, Weber R (2013) Long-term commitment and cooperation. University of Zurich working paper no. 130

Selten R, Stoecker R (1986) End behaviour in sequences of finite prisoner's dilemma supergames: a learning theory approach. J Econ Behav Organ 7:47-70

Stahl D (2013) An experimental test of the efficacy of a simple reputation mechanism to solve social dilemmas. J Econ Behav Organ 94:116-124

Sutter M, Haigner S, Kocher MG (2010) Choosing the carrot or the stick? Endogenous institutional choice in social dilemma situations. Rev Econ Stud 77:1540-1566

Tyran JR, Feld LP (2006) Achieving compliance when legal sanctions are non-deterrent. Scand J Econ 108:135-156

Publisher's Note Springer Nature remains neutral with regard to jurisdictional claims in published maps and institutional affiliations. 